\title{
ACCIÓN AFIRMATIVA EN LA JURISPRUDENCIA DEL TRIBUNAL CONSTITUCIONAL
}

\author{
AFFIRMATIVE ACTION IN THE JURISPRUDENCE OF THE \\ CONSTITUTIONAL COURT.
}

\author{
Rodolfo Figueroa G. ${ }^{*}$
}

\begin{abstract}
RESUMEN: Este trabajo analiza en qué medida es compatible la acción afirmativa con la jurisprudencia del Tribunal Constitucional. Se revisaron cerca de 140 casos. El Tribunal Constitucional no ha abordado ningún caso en que esté en discusión la acción afirmativa, pero la ha validado expresamente en uno de sus fallos. En ninguna sentencia el tribunal ha emitido considerando alguno en contra de la constitucionalidad de la acción afirmativa. Ministros disidentes la han reconocido en varios casos. La doctrina del tribunal en materia de igualdad y no discriminación es perfectamente compatible con la acción afirmativa.
\end{abstract}

Palabras clave: Acción Afirmativa, Jurisprudencia, Tribunal Constitucional.

ABSTRACT: This paper analyzes to which extent affirmative action is compatible with the jurisprudence of the Constitutional Court. 140 cases have been revised. No case where affirmative action was the core issue has been decided by the court. However, it has validated affirmative action in one of its decisions. There is not a single decision where the Constitutional Court had objected the constitutionality of affirmative action. Dissenting opinions of several justices have supported affirmative action in a variety of cases. The Constitutional Court's doctrine on equality and non-discrimination is perfectly compatible with affirmative action.

Key words: Affirmative Action, Jurisprudence, Constitutional Court.

\section{INTRODUCCIÓN}

El objetivo de este trabajo es mostrar qué grado de compatibilidad existe entre la jurisprudencia del Tribunal Constitucional chileno (en adelante, el TC) y lo que la doctrina denomina acción afirmativa. Esta investigación forma parte de la arista jurídico-constitucional de un proyecto de investigación Fondecyt relativo a ciudadanía para las mujeres en una sociedad multicultural.

La relevancia de esta investigación reside en que la acción afirmativa es una institución que se pretende introducir en el sistema electoral para mejorar la participación de la

\footnotetext{
* Doctor en Derecho, Profesor de Derecho Constitucional, Facultad de Derecho, Universidad Diego Portales. Dirección postal: Av. República 105, Santiago de Chile. Dirección electrónica: rodolfo.figueroa@udp.cl

1 El presente trabajo forma parte del Proyecto FONDECYT No 1120566 titulado "Ciudadanía para las mujeres en una sociedad multicultural. Hacia la construcción de una concepción deliberativa con vocación universal y su impacto institucional" en el cual el autor participa como coinvestigador. El autor agradece los comentarios de Luis Villavicencio Miranda, investigador responsable del proyecto.
} 
mujer en cargos de elección popular ${ }^{2}$. Eso se ha hecho en más de cien países en el mundo ${ }^{3}$. Una primera pregunta obvia frente a esa política es si la acción afirmativa es constitucional; dicho de otro modo, si resulta compatible con la Constitución chilena a partir de un análisis dogmático. A esta interrogante se ha dedicado otro artículo ${ }^{4}$. Una segunda pregunta es si dicha institución ha sido reconocida o validada por el TC y/o si es compatible en términos teórico-dogmáticos con la doctrina del TC en materia de igualdad y discriminación. Estas preguntas son relevantes para el caso en que las normas que instituyan la acción afirmativa en la ley electoral sean impugnadas ante el TC, o para cualquier otro caso en que una ley intente recoger alguna medida de acción afirmativa.

\section{ACCIÓN AFIRMATIVA}

En la literatura jurídica existen varias formas de referirse a la acción afirmativa: discriminación positiva, discriminación inversa ${ }^{5}$ y acciones positivas ${ }^{6}$. En la literatura angloamericana es frecuente la expresión affirmative action, en particular a partir del caso Bakke ${ }^{7}$. En la doctrina chilena se usan todas estas fórmulas ${ }^{8}$. Existe jurisprudencia chilena que ha acogido esta terminología ${ }^{9}$ e incluso existe un caso en que la Corte Suprema, resolviendo

2 El Congreso Nacional aprobó modificaciones a la LEY N¹8.700, orgánica constitucional sobre Votaciones Populares y Escrutinios. La que es pertinente a acción afirmativa es el artículo $3^{\circ}$ bis inciso $5^{\circ}$ : "De la totalidad de declaraciones de candidaturas a diputado o senador declaradas por los partidos políticos, hayan o no pactado, ni los candidatos hombres ni las candidatas mujeres podrán superar el sesenta por ciento del total respectivo. Este porcentaje será obligatorio y se calculará con independencia de la forma de nominación de las candidaturas. La infracción de lo señalado precedentemente acarreará el rechazo de todas las candidaturas declaradas a diputados o a senadores, según corresponda, del partido que no haya cumplido con este requisito.” Así consta en Oficio No 11.685, de 20 de enero de 2015, del Presidente de la Cámara de Diputados a la Presidenta de la República. Agradezco a Nicolás Benkel y Marcela Ríos, del PNUD, por remitirme esta información.

3 Quota project (2013) p. 1.

4 Figueroa (2015).

5 Ver VV.AA. (Dworkin, 1993;1985; Ruiz-Miguel, 1994; 1996).

6 Ver VV.AA. (Ballestrero,1996; Atienza,1996).

7 University of California Regents v. BakKe, (1978).

8 Ver VV.AA. (Figueroa, 2000; Zúniga et al. 2007; Fries, 2011; Medina, 2011; Contesse, 2011; Cornejo, 2011; Carmona, 2011; Bronfman et al. 2012; Nogueira, 2010; Silva, 2006; Zúñiga y Valenzuela, 2014).

9 Se alude a discriminación positiva en:

a) Poblete con Servicio de Registro Civil e Identificación de Chile (2008), Co $3^{\circ}$. "Que si bien debe considerarse, en relación al derecho fundamental de igualdad ante la ley, que siempre debe haber discriminación positiva para personas que, como el recurrente señor Oscar Alberto Poblete González, el Servicio de Registro Civil e Identificación de Chile, le ha otorgado la credencial del Registro Nacional de la Discapacidad, reconociendo que lo afecta en el grado de discapacidad psíquica o mental de un 70,00 \%, discriminación la cual consiste en que dicha persona debe recibir por parte del Estado, que así lo reconoce, un trato más favorable que el general de las personas y no igualitario con estas, sin embargo, ese antecedente por si solo es insuficiente sin más, para dar por establecido en este procedimiento o tener como hecho evidente del mismo, el agravio que dice haber sufrido el recurrente, y que pudiera afectar, además del derecho antes mencionado, la esfera de su libertad, de su derecho de desarrollar cualquiera actividad económica que no sea contraria a la moral, al orden público o a la seguridad nacional, o su libertad de trabajo, razones de por qué este recurso no puede prosperar."

b) I. Municipalidad de Putre C. Comisión Regional del Medio Ambiente de Arica y Parinacota (2011). La expresión aparece en los vistos, donde la corte hace referencia al Convenio 169. No aparece en los considerandos. 
una acción de inaplicabilidad, declaró constitucional artículos de la ley indígena que instituía una forma de acción afirmativa ${ }^{10}$.

En este trabajo se prefiere utilizar la expresión acción afirmativa. Es mejor que la expresión acción positiva que es muy amplia: acciones positivas son acciones destinadas a cumplir un deber positivo, por ejemplo, realizar prestaciones de salud primaria, lo que no implica necesariamente una política de acción afirmativa. Puede haber una conexión entre acción positiva y acción afirmativa, pero no necesariamente ${ }^{11}$. La expresión "acción afirmativa" también es mejor que la expresión "discriminación inversa" o "discriminación positiva" debido al sentido peyorativo que suele envolver la palabra "discriminación".

En el ámbito anglosajón la acción afirmativa está relacionada con acciones destinadas a combatir prácticas discriminatorias, patrones de desventaja y exclusión social ${ }^{12}$ y promover la inclusión de grupos o sectores marginados ${ }^{13}$. Entenderé por acción afirmativa aquellas políticas destinadas a mejorar la inclusión y participación de la mujer y/o grupos que han sufrido exclusión y discriminación de manera sistemática y persistente por largos períodos de tiempo ${ }^{14}$, generando una desigualdad fáctica de tal magnitud que un estatuto formalmente igualitario es incapaz de revertir la desventaja en que se encuentra la mujer o ciertos grupos, de modo que requieren, por lo mismo, medidas de acción afirmativa ${ }^{15}$. En consecuencia, la acción afirmativa no alude a cualquier grupo desventajado sino al que ha sido víctima de una discriminación (directa o indirecta) de carácter sistemático y persistente por largos períodos de tiempo ${ }^{16}$.

\footnotetext{
c) Margarita Ocares Castro con Universidad Central de Chile (2012), Co 8, párrafo 8: "Es decir, aunque fuese cierta la diferencia con relación a otras personas que estarían en su misma condición, aun así esa sola diferencia efectuada por la empleadora no es irreversiblemente discriminación y, es más, si fuese discriminación, debe evaluarse si ella es sancionada, toda vez que en el Derecho hay más de un caso de discriminación, tanto es así que existen casos denominados discriminación positiva. Además, para los efectos de unas pretensiones, la trabajadora se coloca en igualdad con otras ex autoridades de la denunciada, pero para otras, desconoce esas supuestas igualdades, lo que trae aparejado un beneficio económico distinto, como es el caso del reclamo por despido injustificado contenido en el primer otrosí de su demanda, en que reclama que ella no tenía un cargo de aquellos que se puedan desahuciar, como sí aconteció con aquellas personas con quienes se pretende igualar para los efectos que se evite el tope del artículo 172 del Código del Trabajo, pero quienes fueron desahuciados, al igual que ella, en los términos del artículo 161 del Código del Trabajo".

10 El caso Corporación Metodista, Recurso de Inaplicabilidad contra los artículos 53 y 53 bis de la ley indígena. Corte Suprema, Rol 17.058-1993, 25-6-1993. Co 5o: "Que así entendido este derecho resulta fácil deducir que las normas contenidas en los artículos 53 y 53 bis, antes mencionadas, no son inconstitucionales porque los indígenas, en los casos señalados en estos preceptos, tienen un mismo trato y se encuentran en iguales condiciones con los integrantes de la Corporación Metodista que figura como demandada en el juicio reivindicatorio que se tramita en el Juzgado de Letras de Mayor Cuantía de Angol y ningún acto discriminatorio se efectúa al aplicar los referidos artículos, pues es evidente que la dictación de estos tuvo como único propósito la protección de cierta categoría de personas para resguardar su debilidad social, cultural y económica frente a otros estamentos de la sociedad chilena que no se encuentran en las mismas condiciones, como lo son los indígenas del país".

11 Figueroa (2015).

12 BAMFORTH et al. (2008) p. 345.

13 Mccrudden (1986) pp. 219-220.

14 Sobre la mujer como víctima de una discriminación sistemática y persistente en el Estado moderno, ver Balaguer (2005) p. 106. Sobre la inferioridad como producto cultural, de la mujer, ver ZúNígA (2009) p. 44.

15 Ver Figueroa (2000), Figueroa (2015).

16 Figueroa (2015).
} 


\section{METODOLOGÍA DE LA INVESTIGACIÓN.}

La metodología para investigar qué ha ocurrido con la acción afirmativa en la jurisprudencia del TC ha consistido en realizar búsquedas en la base de datos de jurisprudencia del portal del TC. Se hicieron dos tipos de búsqueda, atendiendo a dos objetivos diferentes. El primer objetivo fue averiguar si había casos de acción afirmativa o casos en que se aludiera a ella. Para cumplir ese objetivo se buscó en el portal de sentencias del TC los siguientes conceptos: acción afirmativa, discriminación positiva, discriminación inversa, acciones positivas, discriminación inversa y affirmative action. Las búsquedas se realizaron sin límite de tiempo hasta el 12 de noviembre de 2014. Se hallaron 12 casos. A esta lista se agregó un caso citado en uno de esos fallos. El total es 13 casos.

El segundo objetivo era determinar en qué medida la doctrina dogmática del TC sobre igualdad es conciliable con la acción afirmativa. Para lograrlo era necesario buscar y sistematizar la jurisprudencia del TC sobre igualdad. Ahora bien, no era razonable buscar dicha jurisprudencia utilizando como criterio la expresión "igualdad" por dos razones. Primero, porque son muchos casos. En efecto, con esa voz aparecen casi novecientas sentencias. Segundo, porque es muy genérica: la palabra igualdad puede aparecer en muchos contextos en los fallos, que no tengan ninguna relación con acción afirmativa. Por ello, era necesario refinar el criterio de búsqueda. Ahora bien, la acción afirmativa consiste en una discriminación (en sentido positivo) de modo que es razonable suponer que se debe buscar doctrina del TC que aborde lo que en Chile se conoce como "discriminación arbitraria". En efecto, parece poco probable que el TC aborde la constitucionalidad de normas que instituyen diferencias y resuelva si son admisibles o no sin recurrir a la expresión "discriminación arbitraria". Por ello, se utilizó dicha expresión en las búsquedas. Aparecieron 127 sentencias. Las búsquedas se realizaron sin límite de tiempo hasta el 12 de noviembre de 2014, como en la primera búsqueda. La mayoría de los casos hallados bajo la primera búsqueda aparecieron en esta segunda. Todos los casos hallados en la segunda búsqueda fueron revisados: se eliminaron 81 porque no decían prácticamente nada sobre igualdad y discriminación y se agregaron 13 casos que aparecían citados en algunos de ellos. Esto dio un total de 48 casos utilizados para examinar la doctrina sobre igualdad.

Por tanto, el total de casos que finalmente aparecen citados en esta investigación, correspondientes a la primera y segunda búsqueda, es 61 .

\section{RESULTADOS DE LA INVESTIGACIÓN.}

En esta sección se expondrán los casos que se seleccionaron para determinar si el TC ha abordado la acción afirmativa y cuál es su jurisprudencia en materia de igualdad y discriminación. En una primera sección se exponen los casos que aparecieron bajo las búsquedas por "acción afirmativa", "acción positiva”, "discriminación positiva”, "discriminación inversa" y "affirmative action". Además, se incluye el caso Rol 2387 que apareció citado en uno de ellos. La segunda sección sigue una ordenación diferente. Dado que el objetivo es conocer la jurisprudencia del TC en materia de igualdad y discriminación, no tiene sentido explicar cada caso por separado. Más bien, se sistematizaron todos los casos a partir de cier- 
tos criterios, para ordenar de manera clara la doctrina del TC en materia de igualdad y discriminación. Esto permite apreciar qué ideas sustantivas ha señalado el TC sobre igualdad y discriminación y cuan reiterada es esa doctrina

\section{IV.I. PRIMERA PARTE}

Como se anunció, en esta parte se explicarán los 13 casos que aparecieron por la búsqueda de "acción afirmativa", "acción positiva”, "discriminación positiva", "discriminación inversa" y "affirmative action".

\section{ACCIÓN AFIRMATIVA}

Buscando en la base de jurisprudencia del TC la expresión "acción afirmativa" aparece un fallo: se trata del caso Rol 2324-12, del 20-11-2012, que consiste en un control de constitucionalidad preventivo de carácter obligatorio, relativo a la LOC de elecciones primarias. La expresión "acción afirmativa" aparece dos veces en el fallo. Primero, como cita del artículo 16 inciso $2^{\circ}$ del proyecto:

"Los partidos políticos cuyos estatutos dispongan medidas de acción afirmativa procederán conforme a ellas al seleccionar sus candidaturas para las elecciones primarias".

Segundo, la referida expresión aparece en un voto de ministro Viera-Gallo que alude al mismo precepto.

Al respecto cabe señalar dos cosas. Por una parte, la ley no establece una política de acción afirmativa que esté bajo revisión ante el TC. Por tanto, este no es un caso de acción afirmativa. Segundo, la expresión "acción afirmativa" es mencionada como una mera referencia a la ley; no constituye una categoría jurídica que haya sido empleada por el TC en su razonamiento jurídico. Por tanto, no encontramos en este fallo ningún elemento de utilidad para la acción afirmativa.

\section{AcCión POSITIVA}

Buscando en el portal del TC la expresión "acción positiva", aparecen tres fallos: Rol 976-07, Rol 2110-11 y Rol 2358-12.

a) El caso Rol 976-07, de 26-6-2008, corresponde a un recurso de inaplicabilidad deducido por Silvia Peña Wasaff respecto del artículo 38 ter de la Ley No 18.933 (Ley de Isapres), en un recurso de protección interpuesto en contra de la Isapre ING Salud S.A., Rol de Ingreso No 4972-2007, ante la Corte de Apelaciones de Santiago. En el Co 28, el TC transcribe un pasaje de un libro de Gregorio Peces-Barba, donde se explica que los derechos sociales son:

"Derechos de prestación (...) que suponen una acción positiva, normalmente de los poderes públicos, aunque también pueden ser los particulares más excepcionalmente, para ayudar a la satisfacción de necesidades básicas, que no pueden ser resueltas por la propia y excesiva fuerza del afectado (...)."

Sobre lo anterior se deben indicar tres cosas. Primero, en este caso se está discutiendo la constitucionalidad de normas que permiten a las isapres cobrar más a las mujeres por sus planes privados de salud. Por tanto, este no es un caso de acción afirmativa. Segundo, la 
expresión "acción positiva" no es utilizada por el TC como parte de su razonamiento jurídico sino que forma parte de una referencia bibliográfica. Tercero, en la referencia bibliográfica que cita el TC, la expresión "acción positiva" está empleada como correlato de deberes de acción y como opuesto a deberes de abstención. Aludida en tal sentido, la referencia es muy amplia y no implica necesariamente una política de acción afirmativa. Por tanto, en esta sentencia tampoco existen elementos de utilidad para la acción afirmativa.

b) El caso Rol 2110-11, de 16-10-2012, corresponde a un recurso de inaplicabilidad por inconstitucionalidad deducido por Hernán del Tránsito Orellana, Presidente del Sindicato Nacional Interempresa de Trabajadores del Transporte de Pasajeros Interurbano Rural y Cargo, en contra del inciso primero del artículo 25 del Código del Trabajo, en autos caratulados "Orellana con Empresa de Transportes Tur Bus Limitada”, en tramitación ante el Segundo Juzgado de Letras del Trabajo de Santiago, RIT O-1589-2011. La expresión "acción positiva" aparece en este fallo en una parte en que el TC explica en qué consiste la inconstitucionalidad por omisión y qué tribunales constitucionales la han reconocido. Señala en el Co 9 párrafo $3^{\circ}$ :

"La omisión que merece un reproche constitucional también puede implicar una acción positiva del legislador contraria al principio de igualdad al introducir una discriminación arbitraria. En ambos casos el control de constitucionalidad se refiere a lo que la norma calla o no dice, lo que debe desprenderse directamente de su texto".

Dos puntos cabe hacer. En primer lugar, en este caso se está discutiendo la constitucionalidad de una norma legal que permite a las empresas no pagar a los choferes el tiempo no trabajado que se produce entre turnos durante los cuales los trabajadores se encuentran a disposición del empleador. Por ende, este no es un caso de acción afirmativa. En segundo lugar, la expresión "acción positiva" se utiliza como algo opuesto a acciones negativas, de modo que carece de relación con acción afirmativa. En consecuencia, este tampoco es un caso que facilite elementos de análisis para la acción afirmativa.

c) El caso Rol 2358-12, del 9-1-2013, corresponde a un requerimiento de constitucionalidad formulado por un grupo de diputados respecto del artículo 9 del proyecto de ley de televisión digital terrestre, Boletín 6190, impugnándose la norma que prohíbe el uso de people meter online. En un voto disidente, se sostiene:

"Esta Magistratura ha señalado que la expresión "sin censura previa" equivale a "sin interferencia de nadie" (STC 226/1995) y puede consistir no solo en una acción negativa (impedir la difusión), sino también puede consistir en una acción positiva: imponer que se entregue una información (STC 226/1995)”.

$\mathrm{Al}$ igual que en el caso anterior, cabe señalar dos cosas: que este no es un caso de acción afirmativa porque se discute la prohibición de usar el people meter, que nada tiene que ver con ella; y que la expresión "acción positiva" se utiliza por oposición a "acción negativa”. Por ende, no hay en este caso nada relevante para la acción afirmativa.

\section{DisCRIMINACIÓN POSITIVA}

Buscando en la base de datos del TC la expresión "discriminación positiva", aparecen 8 fallos: Rol 1683-10, Rol 2250-12, Rol 2357-12, Rol 2503-13, Rol 2482-13, Rol 2440 13, Rol 2523-13 y Rol 2541-13. 
a) El caso Rol 1683-10, de 4-1-2011, corresponde a un requerimiento de inaplicabilidad presentado por Jorge Washington respecto del artículo 365 del Código Penal, en la causa RIT N 1287-2008, RUC Nº800242317-1, seguida ante el Juzgado de Garantía de Cañete. La expresión "discriminación positiva" aparece mencionada en un voto disidente, suscrito por los ministros Vodanovic, Carmona y Viera-Gallo, que analiza el principio de igualdad; en qué consiste y las excepciones al mismo:

Co 18: "La excepción a lo anterior está constituida por la llamada "discriminación positiva”, que la ley puede establecer a favor del más débil, incluso en materia penal. Nuestro sistema jurídico acepta esta postura...”

Respecto de este caso, cabe señalar que un defensor penal público está desafiando la constitucionalidad de una norma penal que sanciona el acceso carnal a un menor de 18 años del mismo sexo cuando no sea violación ni estupro. Se impugna esta norma en el contexto del Código Penal, que no castiga las relaciones entre hombre y mujer libremente consentidas cuando cualquiera de ellos sea menor de 18 años y mayor de 14, o entre dos mujeres siendo una de ellas menor de 18 y mayor de catorce, o entre dos hombres siendo uno de ellos menor de 18 y mayor de 14 si es el menor el que accede carnalmente al otro. Por tanto, no se sanciona la relación carnal que involucra a un menor si la relación es heterosexual, ni si es homosexual femenina, ni se es homosexual masculina pero es el menor el que accede al mayor. El código está penalizando la homosexualidad masculina cuando un mayor de edad accede carnalmente a un menor de edad.

El defensor público considera que esta norma es discriminatoria y persigue a una minoría sexual. Así las cosas, en la lógica del reclamo del desafiante, este no es un caso de acción afirmativa. Además, la norma penal que protege a un menor de edad en el específico caso señalado tampoco parece constituir una medida de acción afirmativa.

El voto de mayoría rechaza la impugnación y justifica el trato diverso que la norma introduce pues se funda en "...los principios del interés superior del niño y de protección especial, contemplados en instrumentos de derecho internacional..."17 Agrega la mayoría:

"El legislador $(\ldots)$ ha obrado dentro de la órbita de sus potestades constitucionales al referir la protección del menor, en materia de autodeterminación e indemnidad sexual, a las relaciones sodomíticas en que juega un papel pasivo, por entender, razonablemente, que se trata de un tipo de relación lesiva de su dignidad como persona, afincada en la inmadurez de su desarrollo psíquico y sexual".

Como se puede advertir, el voto de mayoría justifica el trato diverso que se da a esta situación, comparada con las otras que señaló el defensor público requirente, en el hecho de que el menor es inmaduro y necesita protección. Pues bien, esta argumentación en favor de una diferencia no parece constituir una defensa de la acción afirmativa.

Finalmente, cabe referirse al voto de minoría. Los ministros disidentes formulan criterios interpretativos para analizar el caso, entre ellos, las llamadas "categorías sospechosas", que exigen "...un análisis más riguroso y exigente del principio de igualdad..." 18 ya que pueden someter “.... grupos minoritarios especialmente vulnerables a un trato discrimina-

17 Rol 1683, Co 31.

18 Rol 1683, Co 18 del voto de minoría. 
torio. Ello implica que la discriminación por sexo, una categoría paradigmáticamente sospechosa, debe pasar un escrutinio estricto" ${ }^{19}$. Agregan que el principio de igualdad prohíbe a la ley establecer diferencias basadas en la raza, la opinión, o el sexo y precisan que una excepción a lo anterior es la discriminación positiva pues ella permite proteger al más débil. Nada más dicen de la acción afirmativa. Por tanto, cabe concluir que los ministros disidentes consideran que la acción afirmativa es compatible con el principio de igualdad y, por ende, con la Constitución, aunque no sea este un caso de acción afirmativa.

b) El caso Rol 2250-12, de 18-6-2013, se refiere a un recurso de inaplicabilidad presentado por Carolina Llanos, Juez titular del Juzgado de Garantía de San Pedro de La Paz, y Luz Celedón y Paola Rivas, Juezas titulares del Cuarto Juzgado de Familia de Santiago, respecto de la $1^{\text {a }}$ parte inciso $2^{\circ}$ del artículo $6^{\circ}$ de la Ley $\mathrm{N}^{\circ} 20.545$, que modifica normas sobre protección a la maternidad e incorpora el permiso postnatal parental, en autos acumulados sobre Recurso de Protección, ante la Corte de Apelaciones de Santiago, Rol N ${ }^{\circ}$ 5051-2012.

En voto disidente, los ministros Carmona, García y Viera-Gallo aluden de manera expresa la discriminación positiva. Señalan en el Co 36:

“...las medidas de protección de la maternidad son medidas de discriminación positiva, en que el Estado favorece a las madres, como una manera de compensar o corregir la situación de desventaja en que quedan por ese hecho. No se genera, por tanto, una situación activa de ventaja que sustraiga a cierto grupo de reglas comunes de manera abusiva y sin justificación. Lo que se busca es, precisamente, generar una regulación que permita nivelar la cancha respecto de las madres. Se materializa el mandato constitucional de "promover la integración armónica de todos los sectores de la Nación” y "asegurar" la "igualdad de oportunidades en la vida nacional" (artículo $1^{\circ}$, Constitución).”

En este caso se impugnan normas que reducen el sueldo de las madres que se acogen al posnatal parental. En tal sentido, este no es un caso de acción afirmativa. El voto de mayoría rechaza el requerimiento, sin ninguna consideración pertinente a nuestro tema.

El voto de minoría sí alude a la acción afirmativa, como acabamos de ver, y lo hace para validarla. Primero, señala que la discriminación positiva es una medida que favorece a un grupo, y se justifica por la situación de desventaja en que se encuentra. Segundo, añade que por estar en situación de desventaja, las medidas que favorecen a ese grupo no lo colocan en posición aventajada respecto de los demás. Tercero, indican que esta política está justificada y no es abusiva. Aplicado a este caso, los disidentes argumentan que las medidas de acción positiva en materia de maternidad se justifican porque permiten "nivelar la cancha” para las madres. En cuanto al fundamento constitucional de la acción afirmativa, los disidentes lo encuentran en el artículo $1^{\circ}$ de la Constitución, que demanda promover la integración armónica de todos los sectores de la nación y asegurar la igualdad de oportunidades de todas las personas en la vida nacional.

En consecuencia, aunque este no sea un caso de acción afirmativa, tenemos aquí un reconocimiento explícito y justificación constitucional de la misma, de parte de los ministros disidentes.

19 Rol 1683, Co 18 del voto de minoría. 
c) El caso Rol 2357-12, de 4-7-2013, consiste en un recurso de inaplicabilidad presentado por Leyla Alejandra Chahín Valenzuela y otros Fiscales del Ministerio Público, respecto del inciso $2^{\circ}$ del artículo 6 de la Ley $\mathrm{N}^{\circ} 20.545$, que modificó las normas sobre protección a la maternidad e incorporó el permiso postnatal parental, en los autos sobre Recurso de Protección, ante la Corte de Apelaciones de Santiago, Rol N³6.370-2012.

En este caso sucede lo mismo que en el anterior. Los ministros Carmona y García suscriben un voto idéntico al ya señalado, también en el Co 36.

d) El caso Rol 2503-13, de 13-3-2014, se trata de una acción de inaplicabilidad deducida por varias abogadas y fiscales del Ministerio Público, en contra de la primera parte del inciso segundo del artículo $6^{\circ}$ de la Ley $\mathrm{N}^{\circ} 20.545$, que modificó las normas sobre protección a la maternidad e incorporó el permiso postnatal parental.

Este caso es análogo a los dos anteriores y, de hecho, el voto de mayoría los cita expresamente, roles 2250 y 2357. De igual manera, tenemos el voto disidente de los ministros Carmona y García, al que se suma el ministro Vodanovic. En el Co 36 estos ministros reiteran lo señalado con anterioridad. Por tanto, doy por reiteradas las mismas conclusiones.

e) El caso Rol 2482-13, de 19-6-2014, es un recurso de inaplicabilidad planteado por una ingeniera de estudios de la Superintendencia de Casinos, en contra de las normas sobre posnatal parental de la ley No 20.545 .

La situación es análoga a la ya relatada: los ministros disidentes reconocen de manera expresa la discriminación positiva en el Co 36 . Por lo mismo, doy por reproducido el análisis y conclusiones precedentes.

f) El caso Rol 2440-13, de 24-9-2013, corresponde a un requerimiento de inaplicabilidad presentado por la Corte Suprema respecto del artículo $3^{\circ}$ c) de la Ley $\mathrm{N}^{\circ} 12.522$, en un recurso de casación en el fondo, expediente caratulado "Ríos Álvarez Gloria con Instituto de Normalización Previsional (INP)", de que conoce la misma Corte Suprema con el Rol No 8.600-12. En este caso se discute si una norma que concede un montepío puede establecer una diferencia entre hijas casadas y solteras y si dicha diferencia es arbitraria o no.

En el fallo aparece la expresión "discriminación positiva” pero en los Vistos, invocada por el Instituto de Previsión Social, no por el TC. El voto de mayoría rechaza el requerimiento porque la norma impugnada no es decisoria ${ }^{20}$.

En voto que concurre en la decisión pero no en sus fundamentos el ministro Vodanovic señala que el fundamento histórico de la norma era que las hijas solteras cuidaban a los padres, “...menoscabando sus posibilidades de inserción en el mercado laboral y dejándola en una situación desmedrada al momento de morir aquéllos" ${ }^{21}$. Agrega que:

"Dicha situación es la que se buscó enfrentar con pensiones de este tipo, por lo que, a la fecha de su emisión, estas normas eran desarrollo y consagración de prestaciones para

20 La peticionaria se encontraba casada al momento de fallecer el causante; luego anula su matrimonio y después pide el beneficio. Según el voto de mayoría, lo que se debate “...es la determinación del momento al que se retrotraen los efectos de la nulidad de matrimonio judicialmente declarada, para los fines de determinar si al producirse la delación del beneficio (fallecimiento del causante), la peticionaria del mismo se encontraba casada o soltera." Por tanto, lo que se discute no sería un problema de igualdad. Rol 2440-13, Co 5.

21 Rol 2440-13, Co 13 del voto del ministro Vodanovic. 
cubrir un estado de necesidad social para un grupo determinado y uniforme de personas en una misma situación: la mujer desvalida" ${ }^{22}$.

Por tanto, el ministro Vodanovic está justificando la diferencia y, por ende, el montepío en favor de la hija soltera.

¿Es este un caso de acción afirmativa? Es posible. El fundamento del ministro Vodanovic es que las mujeres solteras, por canon cultural, debían cuidar a sus padres, perjudicando sus oportunidades de desarrollo personal y laboral, quedando en situación desmedrada al morir aquellos. Si adherimos a esta visión y consideramos que dichas mujeres estaban siendo objeto de una discriminación arbitraria por razones socioculturales, entonces es posible pensar que una norma que les confiera ayuda económica -montepío- sea una política de acción afirmativa y el ministro Vodanovic la estaría apoyando. Pero el asunto es discutible.

g) El caso Rol 2523-13, de 30-9-13, consiste en un requerimiento de inconstitucionalidad, conforme el artículo 93 no 16 de la Constitución, formulado por un grupo diputados respecto del D.S. No 40 del Ministerio de Medio Ambiente que aprueba el Reglamento del Sistema de Evaluación de Impacto Ambiental, de 12 de agosto de 2013. El reglamento regula la consulta de los pueblos indígenas. En su requerimiento, los diputados señalan que los pueblos indígenas son un grupo históricamente discriminado y por ello el reglamento debió establecer un procedimiento de consulta que incluya medidas de discriminación positiva.

El voto de mayoría rechaza el requerimiento porque los vicios invocados son vicios de legalidad, no constitucionalidad, pues el reglamento infringiría tratados internacionales, que son normas de rango legal. Además, no es atribución del TC controlar la omisión de parte del ejecutivo, de incorporar un sistema específico de consulta en el reglamento. Finalmente, el TC alude al fallo 2387 del 2013, en el cual se habla de discriminación positiva. Los Ministros Bertelsen, Aróstica y Brahm concurren a la mayoría pero rechazan el Co 23, en el cual se aludió al fallo 2387 y a la expresión "discriminación positiva." El Ministro García formula un voto disidente en el cual afirma que no es razonable la ausencia de legislación que instituya políticas inclusivas que den aplicación a la igualdad por diferenciación:

"En fin, no se puede soslayar el debate acerca de las reglas del trato aplicable tratándose de pueblos indígenas ni tampoco es razonable la ausencia de legislación que implemente medidas que propicien la ejecución de políticas inclusivas que importan la aplicación del principio de igualdad por diferenciación ${ }^{23}$.

En primer lugar, cabe señalar que este no es un caso en que una norma instituya un política de acción afirmativa. Más bien, en opinión de los requirentes, parece ser lo contrario: el reglamento no la instituye, debiendo hacerlo. En segundo lugar, el TC rechaza el requerimiento por tratarse de un conflicto de legalidad y no de constitucionalidad. Finalmente, el ministro García comparte la apreciación de los requirentes de que el sistema de consulta debería incluir un mecanismo inclusivo que potencie el principio de igualdad. Esta afirmación podría aludir a acción afirmativa, pero es muy genérica para sostenerlo.

22 Rol 2440-13, Co 13 del voto del ministro Vodanovic.

23 Rol 2523, Co 7 del voto del ministro García. 
Por tanto, cabe concluir que no encontramos en este caso elementos en favor de la acción afirmativa.

h) El caso Rol 2541-13, de 18-11-2013, constituye un requerimiento de inconstitucionalidad deducido por un grupo de diputados, en conformidad al artículo 93 no 3 de la Constitución, en contra del proyecto de ley que introduce la televisión digital terrestre, Boletín No 6190-19. Este proyecto obliga a los concesionarios a promover el pluralismo y excluir lo que atente contra él; obliga a transmitir campañas de utilidad e interés público; impide tener una segunda concesión, salvo para TVN y obliga a permisionarios a transmitir canales regionales (must carry). En el fallo, los ministros disidentes Aróstica y Brahm aluden a la ley 20.694 que modifica la ley 19.132 que regula TVN, en cuya tramitación se habría aludido a discriminación positiva, pero la ley no la contempla.

Este no es un caso de discriminación positiva y la referencia a ella de parte de los ministros disidentes es meramente tangencial de suerte que no es relevante. Por tanto, no encontramos en este fallo elementos en favor de la acción afirmativa.

\section{DISCRIMINACIÓN INVERSA Y AFFIRMATIVE ACTION}

Buscando en el portal de jurisprudencia del TC las expresiones "discriminación inversa" hubo cero resultados. Lo mismo ocurrió cuando se buscó por "affirmative action".

5. El Fallo 2387-12, de 2013

En las búsquedas conforme a los criterios antes explicitados no apareció el fallo Rol 2387-12, pero sí apareció mencionado en el caso Rol 2523-13 como un caso en que se alude a discriminación positiva. Por ello se incluye en este análisis.

El caso Rol 2387-12, de 23-1-2013, corresponde a un requerimiento de control preventivo de constitucionalidad de un proyecto de ley que modifica la ley general de pesca. A este rol se acumuló otro requerimiento, Rol 2388-12. El TC estima que el núcleo del cuestionamiento es puramente formal: haberse omitido en la tramitación de la ley el cumplimiento de normas del Convenio 169, en particular, no haberse realizado consultas a los pueblos indígenas y no haber dado cumplimiento a normas que establecen deberes de respetar y proteger derechos de los pueblos originarios ${ }^{24}$. El TC desestimó el requerimiento por considerarlo excesivamente general e impreciso, inconexo, y por no lograr “....articular un razonamiento constitucional consistente que alcance a configurar una real cuestión de constitucionalidad..." 25 .

En una parte del fallo, el TC se refiere a la autoejecutividad de un tratado internacional y al cumplimiento de sus deberes por parte del legislador, impuestos por el Convenio 169. Afirma el TC:

"Es el legislador quien debe definir las autoridades u organismos representativos de las etnias originarias con derecho a participar en la consulta; la oportunidad y forma de

24 Rol 2387, $\mathrm{Co}^{\circ} 2^{\circ}$ y 3.

25 Rol 2387, Co 6. 
participación en los procesos legislativos pertinentes, de modo libre, informado y no coaccionado, además de fijar el procedimiento" ${ }^{26}$.

A partir de ello el TC formula un comentario en que hace alusión a la discriminación positiva:

"Solo en esas condiciones este Tribunal Constitucional estará en situación de controlar si, efectivamente, se han creado condiciones de participación igualitarias para los pueblos indígenas, que equilibren sus oportunidades y propendan a un desarrollo equitativo, franqueando un especial derecho de consulta y participación operativo, que no es sino emanación de la garantía de la igualdad de trato ante la ley, en cuanto importa una medida de discriminación positiva tendiente a corregir, eventualmente, determinadas situaciones disminuidas..." 27 .

Con estos antecedentes se puede advertir que este no es un caso de discriminación positiva (la ley que modifica la ley de pesca). Sin embargo, el TC se refiere a ella como una política que el parlamento debería adoptar y que sería emanación del principio de igualdad. Por tanto, en este caso el TC valida expresamente la discriminación positiva como una forma de cumplir con el principio de igualdad.

\section{RESUMEN Y CONCLUSIONES DE LA PRIMERA PARTE}

1. En el caso Rol 1683-10, de 4-1-2011 se impugna el artículo 365 del Código Penal que sanciona el acceso carnal entre adulto y menor de edad del mismo sexo, ambos hombres. No se trata de un caso de acción afirmativa. Sin embargo, los ministros disidentes Vodanovic, Carmona y Viera-Gallo analizan el principio de igualdad y validan expresamente la acción afirmativa pues mediante ella el legislador puede proteger al más débil.

2. En los casos Roles 2250-12, de 18-6-2013, 2357-12, de 4-7-2013, 2503-13, de 13-3-2014 y 2482-13, de 19-6-2014, se impugnan normas sobre protección a la maternidad y permiso postnatal parental, que reducen el sueldo de las mujeres. No son casos de acción afirmativa, pero en todos ellos el voto de minoría de los mismos ministros alude a ella y la valida por su rol protector de grupos desventajados, en particular, las madres (nivelar la cancha). Los ministros disidentes fundan la constitucionalidad de la acción afirmativa en el artículo $1^{\circ}$ de la Constitución, que exige promover la integración armónica de todos los sectores de la nación y asegurar la igualdad de oportunidades de todas las personas en la vida nacional.

3. En el caso Rol 2440-13, de 24-9-2013, se impugnan normas que conceden montepío a las hijas solteras, no a las casadas. Se discute si dicha diferencia es arbitraria o no. Un ministro justifica la diferencia en la situación de desprotección en que se encontraban las mujeres solteras, pues se quedaban cuidando a sus padres, “...menoscabando sus posibilidades de inserción en el mercado laboral y dejándola en una situación desmedrada al momento de morir aquéllos”. Agrega que la norma regula “...un estado de necesidad social

26 Rol 2387, Co 23.

27 Rol 2387, Co 23. 
para un grupo determinado y uniforme de personas en una misma situación: la mujer desvalida". Es discutible si este es un caso de acción afirmativa, pero es posible.

4. En el caso Rol 2523-13, de 30-9-13, se impugna el Reglamento del Sistema de Evaluación de Impacto Ambiental por no incorporar medidas de consulta y de discriminación positiva. En voto disidente, el ministro García alude a “...políticas inclusivas que importan la aplicación del principio de igualdad por diferenciación”. Este no es un caso de acción afirmativa y la referencia que formula el ministro García es muy genérica para entender que alude explícitamente a acción afirmativa.

5. En el caso Rol 2387-12, de 23-1-2013 se impugnan normas de la ley de pesca. Si bien este no es un caso de acción afirmativa, es un fallo muy importante porque el TC la valida expresamente:

"Solo en esas condiciones este Tribunal Constitucional estará en situación de controlar si, efectivamente, se han creado condiciones de participación igualitarias para los pueblos indígenas, que equilibren sus oportunidades y propendan a un desarrollo equitativo, franqueando un especial derecho de consulta y participación operativo, que no es sino emanación de la garantía de la igualdad de trato ante la ley, en cuanto importa una medida de discriminación positiva tendiente a corregir, eventualmente, determinadas situaciones disminuidas...”

Por tanto, el TC valida expresamente la discriminación positiva como una política que el parlamento debería adoptar y sería una emanación del principio de igualdad.

6. No habido ningún caso en que el TC se oponga a la acción afirmativa.

En suma:

a) No tenemos casos de acción afirmativa que el TC haya debido resolver, salvo el caso discutible de las normas de montepío.

b) Existe una referencia explícita y validación de la acción afirmativa por parte del TC en un caso. Nunca el TC se ha opuesto a ella.

c) Existen referencias explícitas y validación de la acción afirmativa por parte de ministros disidentes en varios casos.

\section{IV.II SEGUNDA PARTE}

En esta sección se sistematiza la doctrina del TC sobre igualdad y discriminación, con la finalidad de poder examinar su compatibilidad con la acción afirmativa. La selección de casos se realizó conforme la metodología explicada más atrás. La jurisprudencia analizada se sistematizó sobre la base de 5 criterios, de modo que esta sección se divide en 5 acápites.

\section{NOCIÓN DEL PRINCIPIO DE IGUALDAD}

El principio de igualdad ante la ley es entendido por el TC de la siguiente manera: “...las normas jurídicas deben ser iguales para todas las personas que se encuentren en las mismas circunstancias y, consecuencialmente, diversas para aquellas que se encuentren en situaciones diferentes"28. Esta noción es referida por el TC a la Corte Suprema y también 
a la doctrina ${ }^{29}$. Además, el TC ha mencionado que el principio de igualdad presenta las características de generalidad y abstracción, que implica que “...todos los gobernados son destinatarios de ellas (las normas)" ${ }^{30}$.

\section{DIFERENCIA Y DISCRIMINACIÓN}

Las voces "diferencia” y "discriminación” se emplean como sinónimos por el TC. Así, se habla de diferencias arbitrarias o de discriminaciones arbitrarias ${ }^{31}$. Por tanto, la palabra "discriminación" no implica necesariamente una connotación negativa ${ }^{32}$.

\section{RELATIVIDAD}

El TC ha señalado que la igualdad no es absoluta; la ley debe aplicarse a cada caso según las "diferencias constitutivas" del mismo ${ }^{33}$.

Esta idea es fundamental y puede tener distintas dimensiones. Por un lado, significa que se permite introducir diferencias. Esto es obvio y hace operativa la segunda parte del principio de igualdad: tratar diferente a los que son diferentes. Es a esta dimensión que se refiere la jurisprudencia del TC. Por otro lado, la relatividad significa que la igualdad no se puede implementar de manera absoluta porque al intentar generar igualdad fáctica en algún ámbito se produce, inevitablemente, desigualdad en otros. Esto ha sido destacado por $\mathrm{Sen}^{34}$. No parece haber jurisprudencia que reconozca esta dimensión.

\section{ARBITRARIEDAD}

La arbitrariedad es un concepto central del principio de igualdad y el TC se ha referido a él desde distintas perspectivas. A continuación se intenta una sistematización de los puntos que parecen más relevantes en la jurisprudencia del TC:

\footnotetext{
29 Es frecuentemente citado por el TC el autor argentino Quintana Linares (Rol 28, 1985; Rol 53, 1988; Rol 280, 1998; Rol 790, 2007). También ha citado a Silva Bascunán, por ejemplo, Rol 1710, 2010, Co 99. Sin embargo, en este mismo fallo -caso Isapres- el TC hace una extensa cita de Aristóteles, por la vía de Alexy: "NONAGESIMOCTAVO: Que la jurisprudencia chilena, tanto ordinaria como constitucional, ha trazado una línea interpretativa uniforme sobre la igualdad, algunas de cuyas expresiones más citadas se encuentran en dos sentencias, dictadas casi simultáneamente por el Tribunal Constitucional y por la Corte Suprema, en abril y julio de 1985, respectivamente, que asumieron la difundida y clásica fórmula de Aristóteles, expresada en la Política, III 9 (1280a): "Por ejemplo, parece que la justicia consiste en igualdad, y así es, pero no para todos, sino para los iguales; y la desigualdad parece ser justa, y lo es en efecto, pero no para todos, sino para los desiguales" (Tomada de la nota al pie de página 15 del capítulo octavo de la obra de Robert Alexy: Teoría de los Derechos Fundamentales, ob. cit., p. 385);” Rol 1710, 2010, Co 98.

30 Rol 834, 2008, Co 9.

31 Rol 280, 1998, Co 24.

32 Ver Figueroa (2000) p. 12.

33 Rol 28-85, 1985, Voto disidente del M. Valenzuela; Rol 312, 2000, Co 37o; Rol 790, 2007 Co 21; Rol 784, 2007, Co 19; Rol 1217, 2009, Co 3; Rol 1234, 2009, Co 13; Rol 1365, 2010, Co 29; Rol 1414, 2010, Co 14; Rol 1683, 2011, Co 24; Rol 1801, 2011, Co 14; Rol 1988, 2011, Co 64; Rol 1812, 2011, Co 26; Rol 1816, 2011, Co 26; Rol 1817, 2011, Co 26; Rol 2489, 2014, Co 18

34 SEN (1992).
} 


\subsection{Proscripción de la ARBITRARIEDAD}

El TC ha dispuesto que la diferencia no debe ser arbitraria ${ }^{35}$. Esta es la idea central del principio de igualdad: la interdicción de la arbitrariedad.

Ahora bien, en general, la jurisprudencia del TC ha vinculado la arbitrariedad a la diferenciación, tal como suele hacer la doctrina, pero es necesario destacar que también deben vincularse la arbitrariedad a la equiparación. En efecto, al equiparar también se puede cometer una arbitrariedad, como sería tratar del mismo modo a adultos e infantes ${ }^{36}$. Esta conexión es menos frecuente pero sí ha sido aludida al menos en un fallo del $\mathrm{TC}^{37}$.

\subsection{DeFINICIÓN DE ARBITRARIEDAD}

Esta idea, la más importante del principio de igualdad, ha sido definida por la jurisprudencia del TC recurriendo a diversos conceptos, explicaciones, categorías y enunciaciones lingüísticas que, en ocasiones, se superponen. Se intentará aislarlas:

Una discriminación es arbitraria cuando:

a) la anima un "propósito de hostilidad" para una persona o grupo de personas, o implique "indebido favor o privilegio" 38 . Hablando de igual protección en el ejercicio de los derechos, el TC ha señalado que igualdad jurídica significa que no existen “...privilegios o fueros especiales en razón de nacionalidad, raza, sexo, condición social o situación económica..." 39 .

b) es irracional o no razonable o contraria al bien común ${ }^{40}$.

c) es “...contraria a la ética elemental o a un proceso normal de análisis intelectual" ${ }^{\prime 1}$.

d) es producto del capricho, o fundada en el mero capricho ${ }^{42}$.

e) "desvirtúe la esencia de un derecho" 43 .

35 Rol 28-85, 1985, Voto disidente del M. Valenzuela; Rol 280, 1998, Co 24.

36 Ver Figueroa (2000) pp. 15 ss.

37 Rol 1710, 2010, Co 100.

38 Rol 2433-13, Co 10; Rol 2432-13, Co 10; Rol 2438-13, Co 10; Rol 28-85, 1985, Voto disidente del M. Valenzuela; Rol 280, 1998, Co 24; Rol 986, 2008, Co 32; Rol 1243, 2008, Co 17; Rol 1217, 2009, Co 3; Rol 1414, 2010, Co 15; Rol 1683, 2011, Co 24; Rol 1683, 2011 voto de los Ministros Vodanovic, Carmona y Viera-Gallo, Co 31; Rol 1801, 2011, Co 19; Rol 1988, 2011, Co 65; Rol 1817, 2011, Co 27; Rol 1816, 2011, Co 27; Rol 1812, 2011, Co 27; Rol 1941, 2012, votos de los Ministros Peña y García, Co 7; Rol 1365, 2010, Co 21 .

39 Rol 834, 2008, Co 10.

40 Rol 203, 1994, Co 11; Rol 280, 1998, Co 24. Rol 784, 2007, Co 19; Rol 1217, 2009, Co 4; Irracional o contraria la razón: Rol 1217, 2009, Co 8. Infundada o no razonable: Rol 976, 2008, Co 62; Rol 1710, 2010, Voto de M. Navarro, Co 17. Racional o razonable se toman como sinónimos en la jurisprudencia del TC. Rol 986, 2008, Co 31; Rol 1243, 2008, Co 16; Rol 1153, 2008, Co 62.

41 Rol 986, 2008, Co 31; Rol 1153, 2008, Co 62; Rol 1243, 2008, Co 16; Rol 1217, 2009, Co 8; Rol 1710, 2010, Co 147.

42 Rol 203, 1994, Co 37; Rol 312, 2000, Co 37; Rol 804, 2007, Co 32.

Una combinación entre b) y d) es: infundada y carente de razonabilidad, como afirma el TC en el caso Rol 1502, 2010, Co 3 .

43 Rol 804, 2007, Co 32. 
f) no es objetiva y razonable, o las diferencias "...no estén soportadas en un fin de carácter general y que, en fin, no sean tolerables para quien sufre menoscabo de su derecho" ${ }^{44}$. El TC ha indicado que la razonabilidad y objetividad evitan el libre arbitrio del legislador o de la autoridad ${ }^{45}$.

g) no persigue "fines objetivos y constitucionalmente válidos" ${ }^{36}$.

h) es odiosa, injusta o irracional ${ }^{47}$. El TC ha resuelto que una discriminación es injusta cuando carece de justificación racional o es producto del capricho ${ }^{48}$. Esta formulación es muy interesante porque hace análogos los conceptos de arbitrariedad e injusticia.

Además, el TC ha sostenido que la discriminación arbitraria formulada en términos positivos consiste en que “...debe existir un factor de diferenciación que justifique la diversidad de trato legalmente fijado" ${ }^{49}$. Con esta declaración el TC parece querer sugerir que lo inverso de la discriminación arbitraria es la justificación.

En la letra f) se aprecia que las diferencias deben tener justificación objetiva. Esta declaración es muy reiterada por la jurisprudencia del TC. Sin embargo, en unos pocos casos el TC ha admitido que sí se pueden tomar en cuenta factores subjetivos:

"el principio de la igualdad de trato que deben dar el Estado y sus organismos en materia económica puede presentar diferencias racionales tomando en cuenta la concurrencia de elementos subjetivos o supuestos de hecho distintos" 50 .

\subsection{EXTENSIÓN DE LA ARBITRARIEDAD}

La jurisprudencia del TC ha prohibido la arbitrariedad de manera extensa, sin limitarse al objetivo de la regulación o a sus resultados. Incluso más, el TC ha sostenido que tampoco es admisible la arbitrariedad como medio para lograr un fin. Por tanto, siguiendo la doctrina y la literatura comparada dominante, el TC que resuelto que la arbitrariedad se encuentra proscrita sea como motivación, como medio y como resultado ${ }^{51}$.

\subsection{DiFERENCIA ENTRE ARBITRARIEDAD Y DISCRECIONALIDAD}

El TC ha trazado una distinción entre arbitrariedad y discrecionalidad, aunque no ha sido objeto de mayor elaboración ni reiteración por parte de su propia jurisprudencia.

\footnotetext{
44 Rol 790, 2007, Co 35; Rol 1133, 2008, Co 15. Ver Rol 784, 2007, Co 19: "parámetros objetivos y ajustados a la razón".

45 Rol 1217, 2009, Co3; Rol 1365, 2010, Co 33 (cita Rol 1535, Co 35 y 37); Rol 1414, 2010, Co 16; Rol 1683, 2011, Co 24; Rol 1801, 2011, Co 19; Rol 1817, 2011, Co 28; Rol 1816, 2011, Co 28; Rol 1812, 2011, Co 28.

46 Rol 790, 2007, Co 22, citando a la Corte Suprema de México; Rol 1170, 2008, Co 13; Rol 1234, 2009, Co 13; Rol 755, 2007, Co 40; Rol 1138, 2008, Co 37; Rol 1140, 2008, Co 31; Rol 1414, 2010, Co 17; Rol 1683, 2011, Co 24; Rol 1801, 2011, Co 17; Rol 1817, 2011, Co 30; Rol 1816, 2011, Co 30; Rol 1812, 2011, Co 30; Rol 1941, 2012, voto de los Ministros Peña y García, Co 10.

47 Rol 834, 2008, Co 10. La diferencia o discriminación no debe ser injusta: Rol 249, 1996, Co 9.

48 Rol 249, 1996, Co 9.

49 Rol 1295, 2009, Voto del Ministro Bertelsen, Co 6.

50 Rol 280, 1998, Co 2; Rol 790, 2007, Co 41.

51 Rol 986, 2008, Co 3; Rol 834, 2008, Co 9; Rol 1243, 2008, Co 15.
} 
Así, el TC ha señalado que la arbitrariedad “...es fruto de la mera voluntad o el puro capricho", en tanto, la discrecionalidad “...cuenta con el respaldo mayor o menor, mejor o peor, es otra cuestión de una fundamentación que lo sostiene" 52 .

\subsection{Arbitrariedad y Razonabilidad}

Se ha señalado que el concepto central de la Igualdad es la prohibición de arbitrariedad y sobre este concepto hemos visto que el TC lo ha definido recurriendo a diversas expresiones y categorías, las que se pueden resumir en una idea básica: falta de fundamento o de razones. Esta idea clave de falta de fundamento conduce a otra idea capital: razonabilidad. El TC ha indicado que la igualdad exige que la distinción entre quienes no se encuentren en la misma condición debe ser razonable ${ }^{53}$. Más aún, el TC ha señalado que "la razonabilidad es el cartabón o standard de acuerdo con el cual debe apreciarse la medida de igualdad o la desigualdad" 54 . En muchos fallos ha sostenido que "...un primer test para determinar si un enunciado normativo es o no arbitrario, consiste en analizar su fundamentación o razonabilidad y la circunstancia de que se aplique a todas las personas que se encuentran en la misma situación prevista por el legislador"55.

Se puede sostener, por tanto, que la razonabilidad es la cara opuesta de la arbitrariedad.

\subsection{Triple test de arbitrariedad: Proporcionalidad}

Más atrás se indicó que el TC ha entendido la arbitrariedad de manera amplia, extendiendo la proscripción de la arbitrariedad a la motivación, al medio y al resultado. Pues bien, esos ámbitos le han permitido al TC estructurar una suerte de test de arbitrariedad, que exige examinar el fundamento de una norma o distinción, la legitimidad del fin y los medios utilizados. En sus propias palabras, el TC ha señalado:

"Así, un primer test para determinar si un enunciado normativo es o no arbitrario es si tiene o no fundamentación de algún tipo, resultando arbitrario aquello que carece de fundamento. Ya superada dicha primera barrera, corresponde calificar la legitimidad de la causa de la diferencia de trato y la legitimidad de la finalidad perseguida; para posteriormente llegar a la coherencia de ellas con los medios utilizados, y finalmente arribar al resultado buscado por el legislador" 56 .

\footnotetext{
52 Rol 986, 2008, Co 33; Rol 1243, 2008, Co 18.

53 Rol 28-85, 1985, Voto disidente del M. Valenzuela; Rol 280, 1998, Co 24; Rol 790, 2007 Co 21; Rol 784, 2007, Co 19; Rol 1217, 2009, Co 3; Rol 1234, 2009, Co 13; Rol 1365, 2010, Co 29; Rol 1414, 2010, Co 14; Rol 1683, 2011, Co 24; Rol 1801, 2011, Co 14; Rol 1988, 2011, Co 64; Rol 1812, 2011, Co 26; Rol 1816, 2011, Co 26; Rol 1817, 2011, Co 26; Rol 2489, 2014, Co 18.

54 El TC cita a Linares Quintana. Rol 28, 1985, Co 4; Rol 53, 1988, Co 73; Rol 219, 1995, Co 17; Rol 790, 2007, Co 21; Rol 787, 2007, Co19; Rol 797, 2008, Co 19; Rol 1273, 2008, Co 57; Rol 1348, 2009, Co 43; Rol 2231, 2012, Co 12; Rol 784, 2007, Co 19; Rol 1217, 2009, Co 3; Rol 1234, 2009, Co 13; Rol 1365, 2010, Co 29; Rol 1414, 2010, Co 14; Rol 1683, 2011, Co 24; Rol 1801, 2011, Co 19; Rol 1988, 2011, Co 64; Rol 1812, 2011, Co 26; Rol 1816, 2001, Co 26; Rol 1817, 2011, Co 26;

55 Rol 1217, 2009, Co 3; Rol 1988, 2011, Co 64; Rol 1817, 2011, Co 27; Rol 1816, 2011, Co 27; Rol 1812, 2011, Co 27; Rol 1941, 2012, votos de Peña y García, Co 7.

56 Rol 986, 2008, Co 33; Rol 1243, 2008, Co 18.
} 
No cabe duda que este test de arbitrariedad corresponde a un test de proporcionalidad. En efecto, examinar medios y fines equivale a hablar de proporcionalidad. Sin embargo, no es necesario tratar de demostrar esto porque el TC ha sido explícito en vincular igualdad y proporcionalidad. En efecto, el TC ha declarado que la diferencia de trato debe ser "proporcionada a la diferencia de hecho existente, teniendo particularmente en cuenta el propósito o finalidad perseguida por el legislador" ${ }^{57}$. En muchos fallos el TC ha sostenido que el examen de proporcionalidad exige incorporar el análisis de "...las situaciones fácticas, la finalidad de la ley y los derechos afectados" ${ }^{58}$. Recurriendo a otras fórmulas lingüísticas, el TC ha indicado que para determinar si una diferencia es constitucional, no solo se exige que tenga un fundamento razonable, sino también la idoneidad de la medida para conseguir el fin previsto por el legislador ${ }^{59}$. Esta triple relación entre fundamento, idoneidad de la medida y fin previsto es una correlación de proporcionalidad.

Con otra enunciación, pero reiterando lo que he señalado, el TC ha resuelto que para determinar si se transgrede el principio de igualdad es necesario examinar la finalidad que tuvo a la vista el legislador, que debe ser adecuada, necesaria y tolerable para el sujeto imperado $^{60}$. Esta doctrina ha sido reafirmada por el TC efectuando citas del Tribunal Constitucional español:

"para que la diferenciación resulte constitucionalmente lícita no basta que lo sea el fin que con ella se persigue, sino que es indispensable además que las consecuencias jurídicas que resultan de tal distorsión sean adecuadas y proporcionadas a dicho fin, de manera que la relación entre la medida adoptada, el resultado que produce y el fin pretendido por el legislador supere un juicio de proporcionalidad en sede constitucional, evitando resultados especialmente gravosos o desmedidos" ${ }^{61}$.

El TC ha citado también a la Corte Suprema de México, que presenta una formulación un poco más esquematizada:

Primero, “...si la distinción legislativa obedece a una finalidad objetiva y constitucionalmente válida...”

Segundo, “...es necesario examinar la racionalidad o adecuación de la distinción hecha por el legislador: es necesario que la introducción de una distinción constituya un medio apto para conducir al fin u objetivo que el legislador quiere alcanzar, es decir, que exista una relación de instrumentalidad entre la medida clasificatoria y el fin pretendido".

\footnotetext{
57 Rol 790, 2007, Co 22; Rol 784, 2007, Co 20.

58 Rol 1170, 2008, Co 13; Rol 1234, 2009, Co 13; Rol 755, 2007, Co 40; Rol 1138, 2008, Co 37; Rol 1140, 2008, Co 31; Rol 1414, 2010, Co 17; Rol 1683, 2011, Co 24; Rol 1801, 2011, Co 17; Rol 1817, 2011, Co 30; Rol 1816, 2011, Co 30; Rol 1812, 2011, Co 30; Rol 1941, 2012, voto de los Ministros Peña y García, Co 10. Legítima, adecuada y proporcional: Rol 1361, 2009, Co 38.

59 Rol 790, 2007, Co 22; Rol 825, 2008, voto del Abogado Integrante Teodoro Ribera, Co 2; Rol 834, 2008, Co 11, Rol 1340, 2009, Co 30; Rol 1563, 2011, Co 14; Rol 1537, 2011, Co 14; Rol 1656, 2011, Co 14; Rol 2081, 2013, voto de los Ministros Vodanovic, Peña, Viera-Gallo y García, Co 6; Rol 1133, 2008, Co 15.

60 Rol 1217, 2009, Co 3; Rol 1234, 2009, Co 13; Rol 1817, 2011, Co 29; Rol 1816, 2011, Co 29; Rol 1812, 2011, Co 29 .

${ }_{61}$ Rol 784, 2007, Co 20; Rol 1812, 2011, Co 29; Rol 1816, 2011, Co 29; Rol 1817, 2011, Co 29.
} 
Tercero, “...debe cumplirse con el requisito de la proporcionalidad: el legislador no puede tratar de alcanzar objetivos constitucionalmente legítimos de un modo abiertamente desproporcional..." ${ }^{62}$.

Esta elaboración mexicana se acerca bastante a la formulación de Alexy sobre el principio de proporcionalidad, que ha sido invocada en Chile ante el TC.

Ahora bien, la conexión que hemos visto entre igualdad y proporcionalidad es más estrecha de lo que se ha señalado hasta aquí, pues en un par de fallos el TC ha sostenido que el principio de igualdad no puede operar sin un examen de proporcionalidad. Esto implica que el principio de proporcionalidad es una condición necesaria del principio de igualdad.

¿Es correcto este nivel de vinculación entre igualdad y proporcionalidad?

Sin duda. Como sabemos, el principio de igualdad requiere tratar igual a los que son iguales y tratar diferente a los que son diferentes. Sin embargo, todas las personas y todas las situaciones son diferentes. Por tanto, lo que hacemos cuando aplicamos el principio de igualdad es, por una parte, considerar irrelevantes algunas diferencias entre personas y/o situaciones y tratar esas personas y/o situaciones del mismo modo (equiparar) y, por otra, considerar algunas diferencias relevantes, recogerlas y brindar un trato distinto a esas personas y/o situaciones (diferenciar) ${ }^{63}$. Saber qué diferencias son relevantes o irrelevantes para acogerlas o rechazarlas supone disponer de algún criterio de relevancia -de justicia- conforme al cual la equiparación o la diferenciación pueda estimarse correcta o justificada ${ }^{64}$. Los criterios de relevancia o irrelevancia de las diferencias fácticas son criterios de justificación para equiparar o diferenciar, y cuando hablamos de justificación, de mostrar que algo es correcto, la proporcionalidad cumple un rol fundamental.

Esta línea de razonamiento, que es sensata a nivel teórico, ha sido recepcionada por el TC, citando jurisprudencia alemana. El TC ha aludido explícitamente al criterio de relevancia para hacer diferenciaciones:

Se considera "... lesionada la igualdad ante la ley cuando un grupo de destinatarios de la norma, comparados con otro grupo de destinatarios de la norma, son tratados de manera distinta, a pesar de que entre ambos grupos no media ninguna diferencia de tal entidad o importancia que pudiera justificar un tratamiento desigual" 65 .

La frase destacada en cursiva es la que alude a un criterio de relevancia para poder efectuar la diferenciación. Pues bien, el TC ha conectado ese criterio de relevancia con el principio de proporcionalidad, que es lo importante. En efecto, justo después de la cita recién transcrita, el TC señala:

"Para poder dimensionar tales situaciones, esta fórmula requiere expresamente una ponderación en el sentido de examen de proporcionalidad, especialmente respecto de una diferencia de trato de gran intensidad, para lo cual se requiere que aquélla persiga un fin

62 Rol 790, 2007, Co 22.

63 Mayores explicaciones, en FigueroA (2000) pp. 18 ss.

64 Figueroa (2000): p. 32.

65 Rol 1710, 2010, Co 100. 
legítimo, que esa búsqueda sea necesaria y que presente una razonable relación con el valor del fin propuesto" ${ }^{6}$.

Se indicó más atrás que el principio de igualdad requiere criterios de relevancia para justificar equiparaciones o diferenciaciones y demostrar que ellas son correctas o justificadas. Hablar de corrección o justificación es hablar de justicia ${ }^{67}$. Pues bien, el TC ha advertido esta conexión cuando vincula proporcionalidad -el núcleo de la igualdad- con legitimidad. En efecto, el TC ha sostenido que una discriminación debe ser legítima ${ }^{68}$ y es legítima cuando es proporcional; más aún, el TC ha declarado que la proporcionalidad es el criterio último de legitimidad ${ }^{69}$.

Por tanto, la arbitrariedad -idea clave de la igualdad-implica fundamento, es decir razones, y la razonabilidad -o legitimidad de una medida- supone un examen de proporcionalidad, que verifique correspondencia entre fundamentos, medios y fines.

Es evidente que determinar la arbitrariedad, esto es, la falta de razones justificatorias o de fundamento, es muy complejo porque se relaciona con lo correcto, lo legítimo, lo bueno, en suma, lo justo ${ }^{70}$, de suerte que hablar de igualdad es hablar de lo justo y sabemos que no existe una sola teoría o concepción de la justicia. Con todo, el TC ha realizado algunas referencias a criterios formales que apunten en alguna dirección para intentar determinar lo justo o lo correcto, y lo ha hecho en muchos fallos. Por ejemplo, en un par de fallos, el TC ha recurrido a un criterio formal invocado por el tribunal constitucional español:

i) que el factor de diferenciación sea necesario para proteger bienes y derechos ${ }^{71}$.

ii) que se trate de "criterios o juicios de valor generalmente aceptados"72.

El primero es una referencia simple a una dimensión de la proporcionalidad: la necesidad de la medida. Por ello, no diremos nada más. El segundo, en cambio, parece más importante: criterios o juicios de valor "generalmente aceptados." Esta fórmula ha sido señalada en quince fallos. La subjetividad o relatividad de las teorías de la justicia se intenta moderar con esta exigencia de que los criterios o juicios gocen de amplia aceptación, es decir, que exista un elevado nivel de consenso en torno a ellos. Es evidente que esta formulación del TC no resuelve problemas de teoría de la justicia, pero esa no es la función del TC, y sí constituye un avance no menor en ese enrevesado camino. Por ejemplo, cuando en la jurisprudencia estadounidense se discuten complejos problemas morales -como permitir el suicidio asistido por un médico- y se invocan derechos fundamentales bajo la protección

\footnotetext{
${ }_{66}$ Rol 1710, 2010, Co 100.

67 RAWLS (1971).

68 Rol 280, 1998, Co 25.

69 Rol 280, 1998, Co 25.

70 RAWLS (1971).

71 Rol 986, 2008, Co 32; Rol 1243, 2008, Co 17.

72 Rol 986, 2008, Co 32; Rol 1243, 2008, Co 17; Rol 1217, 2009, Co 3; Rol 1365, 2010, Co 29; Rol 1988, 2011, Co 65; Rol 1812, 2011, Co 27; Rol 1816, 2011, Co 27; Rol 1817, 2011, Co 27; Rol 1563, 2011, Co 16; Rol 1537, 2011, Co 16; Rol 1656, 2011, Co 16. Rol 1941, 2012, Co 7, votos de los Ministros Peña y García; Rol 1958, 2012, Co 20; Rol 2081, 2013, Co 6, votos de los Ministros Vodanovic, Peña, Viera-Gallo y García; Rol 2133, 2013, Co 35.
} 
de la $14^{\mathrm{a}}$ enmienda, la Corte Suprema ha establecido que es un derecho fundamental aquel que se encuentra profundamente enraizado en la historia y tradición del país, y sin el cual no podría existir ni la justicia ni la libertad ${ }^{73}$. Como se puede advertir, para determinar si existe o no un derecho fundamental -por ejemplo, si el suicidio asistido lo es o no- protegido por el debido proceso sustantivo de la enmienda 14, la corte exige un amplio consenso, o juicios ampliamente aceptados.

\section{TIPOS DE DISCRIMINACIÓN}

El TC ha recogido un par de distinciones fundamentales en materia de discriminación: la discriminación de hecho y de derecho y la discriminación directa e indirecta, las que considera "conceptos clave en relación con la discriminación y la igualdad"74. La primera distinción es conocida en la doctrina nacional desde hace mucho tiempo de modo que no parece necesario hacer algún comentario especial. Sí en cambio resulta muy interesante e importante que el TC haga alusión a la segunda distinción, que incluye la discriminación indirecta, porque es menos difundida a nivel nacional, tanto a nivel de jurisprudencia como de dogmática constitucional. A ella nos referiremos con mayor detalle.

Citando a la Alta Comisionada de Naciones Unidas para los Derechos Humanos, el TC reproduce la distinción entre discriminación directa e indirecta para aplicarla a la discriminación entre hombres y mujeres. En palabras del TC, la discriminación directa consiste en una diferencia que está trazada de manera explícita sobre la base de un criterio considerado discriminatorio, como el sexo u otros. Afirma el TC:

"la discriminación directa se define como una diferencia de trato que consiste en forma explícita en distinciones basadas en el sexo o en una de las categorías reconocidas de discriminación" 75 .

Este tipo de discriminación, la directa o explícita, es lo que en general llamamos "discriminación". Pero esa no es la única forma, obviamente, pues existe también la discriminación indirecta. Esta forma de discriminación es un aporte más reciente en la literatura y en la jurisprudencia.

El TC entiende que la discriminación indirecta es un efecto discriminatorio que produce una norma o una política que formalmente no utiliza ningún criterio de discriminación. Ese efecto se produce debido a la situación fáctica en que se encuentran los destinatarios. En efecto, una norma o política que es neutral en su enunciado normativo puede, empero, producir un efecto discriminatorio debido a las circunstancias a las cuales se aplica. En palabras del TC:

“...la discriminación indirecta se produce cuando una ley, una política o un programa que parecen neutros (por ejemplo en lo que atañe a hombres y mujeres) tienen un

\footnotetext{
73 "Our established method of substantive due process analysis has two primary features: First, we have regularly observed that the Due Process Clause specially protects those fundamental rights and liberties which are, objectively, "deeply rooted in this Nation's history and tradition," (...) ("so rooted in the traditions and conscience of our people as to be ranked as fundamental"), and "implicit in the concept of ordered liberty," such that "neither liberty nor justice would exist if they were sacrificed,"..." WASHINGTON et al. v. GLUCKSBERG, 1997, No. 96-110.

74 Rol 1710, 2010, Co 104.

75 Rol 1710, 2010, Co 104.
} 
efecto discriminatorio en el momento de su aplicación. En ese caso, el resultado o efecto final provoca una situación de desventaja de la mujer con respecto al hombre, debido a las desigualdades existentes no tratadas por una medida supuestamente neutra"76.

Esta forma de entender la discriminación indirecta es compatible con la doctrina especializada ${ }^{77}$.

Es muy interesante notar que el TC explica esta forma de discriminación para el caso de la mujer.

Esta categoría de discriminación indirecta es capital para la acción afirmativa. Las medidas de acción afirmativa se fundan precisamente en la existencia de desigualdades fácticas estructurales y profundamente arraigadas ${ }^{78}$. Por ejemplo, entre hombre y mujeres, entre población indígena y no indígena, entre blancos y negros, etc. Esas diferencias fácticas entre esos grupos son de tal magnitud que normas o políticas formalmente neutrales, es decir, de igualdad formal, no son suficientes para revertir tal desigualdad y, por ende, la perpetúan. Así, una política "formalmente" neutral -que sus enunciados son neutrales en su formulación- puede ser consecuencialmente discriminatoria (discriminatoria indirectamente).

Es posible sostener, entonces, que la discriminación indirecta (un efecto que se produce en la realidad) es uno de los fundamentos de la discriminación positiva (una política destinada a corregirla $)^{79}$.

Ahora bien, es importante señalar que la discriminación indirecta no se limita a las desigualdades fácticas que justifican la acción afirmativa. En efecto, puede haber discriminación indirecta para personas o categorías de personas que no correspondan al tipo de casos que históricamente justifican la acción afirmativa. Por tanto, es necesario tener presente que la discriminación indirecta es más amplia en su cobertura que las desigualdades a que apunta la acción afirmativa.

Volviendo al TC, este declaró que sí se pueden establecer diferencias entre hombres y mujeres y que la igualdad entre ambos grupos no puede ser absoluta ${ }^{80}$.

\section{Resumen Y CONCLUSIONES DE LA SEGUNDA PARTE}

1. El TC recoge el entendimiento tradicional del principio de igualdad, el que es posible encontrar en cualquier texto de doctrina, nacional o extranjera.

2. El concepto de arbitrariedad está desarrollado de manera extensa por el TC, en múltiples fallos, abordando diversas aristas. La idea básica es que está permitido hacer diferenciaciones o discriminaciones, siempre que no sean arbitrarias. Las diferencias son arbitrarias cuando:

3. Las anima un propósito de hostilidad en contra de una persona o grupo, o implique un favor o privilegio indebidos.

\footnotetext{
76 Rol 1710, 2010, Co 104.

77 Fredman (2011): P. 177-178; Bamforth et al. (2008): P. 290.

78 Figueroa (2015).

79 Figueroa (2015).

80 Rol 1710, 2010, Co 105.
} 
4. Son irracionales, o no razonables, no son objetivas, o están fundadas en el capricho, o son injustas.

5. No persiguen fines constitucionalmente válidos.

6. La arbitrariedad está prohibida tanto como fin, medio o resultado.

7. El TC ha analizado la arbitrariedad a través del principio de proporcionalidad, conectando los fines (el fundamento de la medida), los medios y los resultados.

8. El TC ha recogido dos distinciones fundamentales en materia de discriminación: la discriminación de hecho y de derecho y la discriminación directa e indirecta.

9. La discriminación indirecta es aquella forma de discriminación que pueden producir normas o políticas formalmente neutrales debido a las particulares situaciones o circunstancias en que se encuentran los destinatarios de dichas normas o políticas.

10. El hecho de que normas o políticas neutrales puedan generar discriminación indirecta es un fundamento poderoso en favor de justificar la constitucionalidad de la acción afirmativa.

\section{CONCLUSIONES GENERALES}

a) En la jurisprudencia del TC no se ha presentado un caso de acción afirmativa, salvo el caso discutible de las normas de montepío.

b) En un caso el TC ha hecho una referencia explícita y una validación de la acción afirmativa. No habido ningún caso en que el TC haya emitido un considerando en contra de la acción afirmativa.

c) En varios casos ministros disidentes ha realizado referencias explícitas y han validado la acción afirmativa.

d) La forma de entender el principio de igualdad por parte del TC es perfectamente compatible con la acción afirmativa:

a. La acción afirmativa constituye una diferencia que puede estar justificada en un caso específico (depende del caso). El TC acepta diferencias justificadas.

b. El TC rechaza discriminaciones arbitrarias. Si la acción afirmativa está justificada, no es arbitraria.

c. Según el TC, una diferencia es arbitraria cuando la anima un propósito de hostilidad en contra de una persona o grupo, o implique un favor o privilegio indebidos. La acción afirmativa no cabe en esta categoría cuando pretende corregir la situación de la mujer o grupos históricamente marginados o discriminados, de manera directa o indirecta.

d. Asimismo, conforme la jurisprudencia del TC, son arbitrarias las diferencias irracionales, no razonables, no objetivas, o las que están fundadas en el capricho, o son injustas. Pues bien, es posible justificar una específica política de acción afirmativa para que no sea irracional, caprichosa o injusta. 
e. Finalmente, es arbitraria -según el TC- la diferencia que no persigue fines constitucionalmente válidos. Pues bien, la acción afirmativa pretende promover la integración armónica de todos los sectores de la nación, que es un fin constitucionalmente exigible, además de estar señalado de manera expresa en el artículo $1^{\circ}$ de la Constitución.

f. El TC ha reconocido la discriminación indirecta, que es un fundamento importante en favor de la constitucionalidad de la acción afirmativa.

e) Que la noción de "discriminación arbitraria” que emplea el TC sea compatible con la permisión de la acción afirmativa y que el mismo TC haya reconocido la acción afirmativa, además de varios ministros disidentes en varios casos, no significa que si en el futuro se presenta un caso de acción afirmativa, el TC vaya necesariamente a acogerlo. Eso dependerá de la política en cuestión y del caso específico. Pero sí significa -lo que no es poco- que su doctrina previa sobre el principio de igualdad y no discriminación es compatible con permitir la acción afirmativa.

\section{BIBLIOGRAFÍA CITADA}

Atienza, Manuel (1996): “Un comentario al caso Kalanke”, Doxa, No 19: pp. 111-122.

Balaguer, María L (2005): Mujer y Constitución (Madrid, Cátedra).

Ballestrero, María V (1996): “Acciones positivas. Punto y aparte”, Doxa, No 19: pp. 91109.

Bamforth, Nicholas; Malik, Maleiah; O'Cinneide, Colm (2008): Discrimination Law: Theory and Practice (London, Thomson. Sweet \& Maxwell).

Bronfman, Alan; Martínez, José I.; Núñez, Manuel (2012): Constitución Política Comentada (Santiago, Abeledo Perrot).

Carmona, Carlos (2011): "Acciones afirmativas. Los primeros reconocimientos legales y constitucionales", en instituto nacional de derechos humanos, Seminario Internacional. Igualdad y no Discriminación: estándares y mecanismos para la igualdad real (Santiago, INDH) pp. 88-134.

Contesse, Jorge (2011): "Las demandas de la igualdad y los pueblos indígenas: el caso de la acción afirmativa”, en Instituto Nacional de Derechos Humanos, Seminario Internacional. Igualdad y no Discriminación: estándares y mecanismos para la igualdad real (Santiago, INDH) pp. 65-77.

Cornejo, Pablo (2011): "La importancia de las medidas afirmativas para la igualdad sustantiva de grupos históricamente discriminados. Análisis desde la perspectiva de la diversidad sexual”, en Instituto Nacional de Derechos Humanos, Seminario Internacional. Igualdad y no Discriminación: estándares y mecanismos para la igualdad real (Santiago, INDH) pp. 78-87.

Dworkin, Ronald (1985): A Matter of Principle (Cambridge, Harvard University Press).

Dworkin, Ronald (1993): Los Derechos en Serio (trad. Marta Guastavino, Barcelona, Planeta). 
FigueroA, Rodolfo (2000): "Igualdad y discriminación." Igualdad, Libertad de Expresión e Interés Público. Cuadernos de Análisis Jurídico, 10 (Universidad Diego Portales, Santiago) pp. 9-64.

Figueroa, Rodolfo (2015): “¿Son constitucionales las cuotas de género para el parlamento? Revista Chilena de Derecho, Vol 42, No 1: pp 189-214.

Fredman, Sandra (2011): Discrimination Law (Oxford University Press).

FrIES, Lorena (2011): "Igualdad y discriminación en Chile", en Instituto Nacional de Derechos Humanos, Seminario Internacional. Igualdad y no Discriminación: estándares y mecanismos para la igualdad real (Santiago, INDH) pp. 11-15.

Mccrudden, Christopher (1986): "Rethinking Positive Action", Industrial Law Journal, vol. 15: pp. 219-243.

Medina, Cecilia (2011): "Igualdad y no discriminación, estándares internacionales y medidas de acción afirmativa”, en Instituto Nacional de Derechos Humanos, Seminario Internacional. Igualdad y no Discriminación: estándares y mecanismos para la igualdad real (Santiago, INDH) pp. 15-22.

Nogueira, Humberto (2010): Derechos Fundamentales y Garantías Constitucionales, Tomo 2 (Santiago, Librotecnia).

RaWLs, John (1971): A Theory of Justice (Cambridge, Belknap Press).

Ruiz Miguel, Alfonso (1996): "La discriminación inversa y el caso Kalanke", Doxa, No 19: pp. 123-140.

Ruiz-Miguel, Alfonso (1994): “Discriminación inversa e igualdad." El Concepto de Igualdad. Amelia Valcárcel (comp.) (Editorial Pablo Iglesias, Madrid) pp. 77-93.

SEN, Amartya (1992): Inequality Reexaminated (Cambridge, Harvard University Press).

Silva, Alejandro (2006): Tratado de Derecho Constitucional, Tomo XI (Santiago, Editorial Jurídica de Chile).

ZúNigga, Alejandra; Aguilera, Daniela; VÁsquez, Andrea (2007): "Lejos del Poder. Hacia la implementación de una ley de cuotas en Chile", Revista de Derecho (Valdivia), vol. XX, No 2: pp. 9-30.

Zúñiga, Alejandra; Valenzuela, Cecilia (2014): "Leyes de Cuotas Electorales, Constitución y Democracia”, Inédito.

Zúniga, Yanira (2009): "La 'Generización’ de la Ciudadanía. Apuntes sobre el Rol de la Diferencia Sexual en el Pensamiento Feminista”, Revista de Derecho (Valdivia), vol. XXII, No 2: pp. 39-64.

\section{JURISPRUDENCIA DEL TRIBUNAL CONSTITUCIONAL CITADA}

CONTROL DE CONSTITUCIONALIDAD RESPECTO DEL PROYECTO DE LEY QUE ESTABLECE NORMAS PARA LAS ENTIDADES FINANCIERAS EN LIQUIDACIÓN (1985): Tribunal Constitucional chileno, 8 de abril de 1985, Rol No 28-85.

CONTROL DE CONSTITUCIONALIDAD RESPECTO DEL PROYECTO DE LEY ORGÁNICA CONSTITUCIONAL SOBRE VOTACIONES POPULARES Y ESCRUTINIOS (1988): Tribunal Constitucional chileno, 5 de abril de 1988, Rol No 53-88. 
REQUERIMIENTO DE SENADORES RESPECTO DEL ARTÍCULO $2^{\circ}, N^{\circ} 10$, LETRA A) DEL PROYECTO QUE MODIFICA EL DECRETO LEY $N^{\circ}$ 3.063, DE 1979, SOBRE RENTAS MUNICIPALES Y LA LEY $N^{\circ}$ 17.235, SOBRE IMPUESTO TERRITORIAL, INTRODUCE AL ARTÍCULO 24, INCISO SEGUNDO, DEL MENCIONADO DECRETo LEY (1994): Tribunal Constitucional chileno, 6 de diciembre de 1994, Rol No 203-94.

REQUERIMIENTO DE CONSTITUCIONALIDAD RESPECTO LA TRAMITACIÓN DEL PROYECTO DE REAJUSTE EXTRAORDINARIO DE UN 10 \% A LAS PENSIONES QUE INDICA Y UN AUMENTO ADICIONAL A LA EDUCACIÓN (1995): Tribunal Constitucional chileno, 31 de julio de 1995, Rol No 219-95.

REQUeRIMIENTo DE Diputados RESPECTO DEL PROYECTO DE LEY QUE AUTORIZA EL INCREMENTO HASTA LA CANTIDAD DE \$3.085 MILLONES, TRANSFIRIENDO TALES RECURSOS, POR MEDIO DE LA MODIFICACIÓN DE LA GLOSA No 13 DEL PRESUPUESTO NACIONAL VIGENTE, PARA ABSORBER LAS MAYORES PÉRDIDAS OPERACIONALES DE LA EMPRESA NACIONAL DEL CARBÓN S.A. (1996): Tribunal Constitucional chileno, 4 de noviembre de 1996, Rol No 249-96.

REQUERIMIENTO DE DIPUTADOS ACERCA DEL PROYECTO DE LEY QUE REBAJA LA TASA DE LOS ARANCELES A LAS IMPORTACIONES E INTRODUCE MODIFICACIONES A OTRAS NORMAS TRIBUTARIAS Y ECONÓMICAS (1998): Tribunal Constitucional chileno, 20 de octubre de 1998, Rol No 280-98.

REQuerimiento Respecto del tratado entre la República de Chile y la República de ARGENTINA SOBRE INTEGRACIÓN Y COMPLEMENTACIÓN MINERA (2000): Tribunal Constitucional chileno, 3 de octubre de 2000, Rol No 312-00.

REQUERIMIENTO DE INAPLICABILIDAD RESPECTO DEL ARTÍCULO 595 DEL CÓDIGO ORGÁNICO DE TRIBUNALES (2008): Tribunal Constitucional chileno, 31 de marzo de 2008, Rol No 755-07.

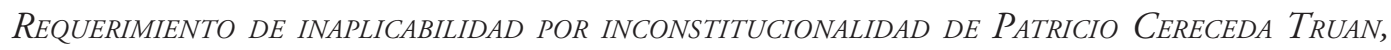
Respecto del artículo 509 del Código de PROCEDimiento Penal (2007): Tribunal Constitucional chileno, 20 de diciembre de 2007, Rol No 784-07.

Requerimiento del Juez Presidente de la Tercera Sala del Tribunal de Juicio Oral en lo Penal de Concepción en relación al artículo 450, inciso primero, del Código Penal (2007): Tribunal Constitucional chileno, 18 de diciembre de 2007, Rol No 787-07.

REQUERIMIENTO DE INAPLICABILIDAD PRESENTADO POR FERNANDO COLOMA REYES Y OTROS RESPECTO DEL ARTÍCULO $4^{\circ}$ DE LA LEY No 18.549 Y DEL ARTÍCULO 29 DE LA LEY No 18.669 (2007): Tribunal Constitucional chileno, 11 de diciembre de 2007, Rol No 790-07.

Requerimiento de la Juez Presidente de la Tercera Sala del Tribunal de Juicio Oral en lo PENAL DE CONCEPCIÓN PARA UN PRONUNCIAMIENTO Y DECISIÓN RESPECTO DE LA APLICABILIDAD o inaplicabilidad del artículo 450, inCiso pRimero, del Código Penal (2008): Tribunal Constitucional chileno, 24 de enero de 2008, Rol No 797-07.

REQUERIMIENTO DE INAPLICABILIDAD DE ÓPTICAS SANTA VICTORIA LIMITADA Y JEANNYE MENESES CUBIDES RESPECTO DE LOS ARTÍCULOS 113, INCISO PRIMERO, 128, INCISO PRIMERO Y 129, INCISO FINAL, TODOS DEL DECRETO CON FUERZA DE LEY N. ${ }^{\circ} 725$ DEL AÑO 1967 (2007): Tribunal Constitucional chileno, 28 de diciembre de 2007, Rol No 804-07.

Solicitud de pronunciamiento y decisión de la Juez PREsidente de la Tercera Sala deL Tribunal de Juicio Oral en lo Penal de Concepción, Respecto de la inaplicabilidad del

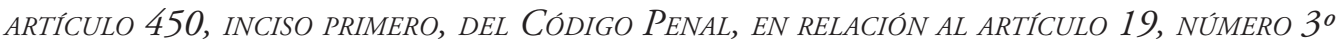
de la Constitución Política de la República (2008): Tribunal Constitucional chileno, 6 de marzo de 2008, Rol No 825-07. 
REQUERIMIENTO DE INAPLICABILIDAD PRESENTADO POR JULIO MAGRI RABAGLIO, RESPECTO DE LOS ARTÍCUlos 188, 199 y 199 BIS DEL CÓdIGO CIVIL (2008): Tribunal Constitucional chileno, 13 de mayo de 2008, Rol No 834-07.

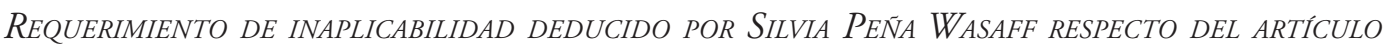
38 TER DE LA LEY No 18.933, CONOCIDA COMO LEY DE ISAPRES (2008): Tribunal Constitucional chileno, 26 de junio de 2008, Rol No 976-07.

REQUERIMIENTO DE INAPLICABILIDAD PRESENTADO POR AARÓN DAVID VÁSQUEZ MUÑOZ, RESPECTO DEL ARTÍ́CUlo 387, inCISO SEGUNDO, DEL Código PROCESAL PENAL (2008): Tribunal Constitucional chileno, 30 de enero de 2008, Rol No 986-07.

REQUERIMIENTO DE INAPLICABILIDAD DE WALDO DEL VILLAR MASCARDI RESPECTO DEL ARTÍCULO 61 DE LA LEY No 20.000, SOBRE TRAFICO ILÍCITO DE ESTUPEFACIENTES Y SUSTANCIAS SICOTRÓPICAS (2008): Tribunal Constitucional chileno, 18 de noviembre de 2008, Rol No 1133-08.

REQUERIMIENTO DE INAPLICABILIDAD POR INCONSTITUCIONALIDAD DEDUCIDO POR MARÍA JOSÉ ARANCIBIA OBRADOR RESPECTO DEL ARTÍCULO 595 dEL CÓdigo ORGANICO DE TRIBUNALES (2008): Tribunal Constitucional chileno, 14 de enero de 2009, Rol No 1140-08.

REQUERIMIENTO DE INCONSTITUCIONALIDAD PRESENTADO POR 16 SENADORES RESPECTO DE LOS DECRETOS Supremos NoS. 45 Y 46, DE 16 Y 20 DE MAYO DE 2008 RESPECTIVAMENTE, DEL MINISterio de TRANSPORTES Y TELECOMUNiCACIONES Y DECRETo SuPREMo No 583, DE 21 DE ABRIL de 2008, del Ministerio de HaCienda (2008): Tribunal Constitucional chileno, 30 de septiembre de 2008, Rol No 1153-08.

CONTROL DE CONSTITUCIONALIDAD DEL PROYECTO DE LEY, QUE ESTABLECE UNA EXCEPCIÓN A LA INHABILIDAD ESTABLECIDA EN LA LETRA B) DEL ARTÍCULO 54 DE LA LEY No 18.575, ORGANICA Constitucional de Bases Generales de la Administración del Estado (BOLETÍN 431306) (2008): Tribunal Constitucional chileno, 26 de agosto de 2008, Rol No 1170-08.

REQUERIMIENTO DE INAPLICABILIDAD DE JOSÉ TOMÁS RoJAS RIVERA RESPECTO DEL ARTíCULO 104 DE LA LEY GENERAL DE BANCOS (2009): Tribunal Constitucional chileno, 31 de enero de 2009, Rol No 1217-08.

REQUERIMIENTO DE INAPLICABILIDAD POR INCONSTITUCIONALIDAD DE ESTADIO CROATA S.A. RESPECTO DEL ARTÍCULO $2^{\circ}$ DE LA LEY No 17.235 (2009): Tribunal Constitucional chileno, 7 de julio de 2009, Rol No 1234-08.

Control de CONSTITUCIONALIDAD DEL PROYECTO DE LEY, APROBADO POR EL CONGRESO NACIONAL, QUE FORTALECE Y PERFECCIONA LA JURISDICCIÓN TRIBUTARIA (2008): Tribunal Constitucional chileno, 30 de diciembre de 2008, Rol No 1243-08.

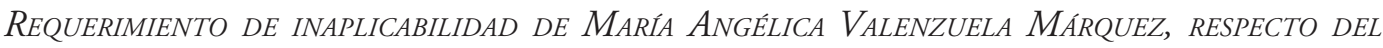
ARTÍCULO 38 TER DE LA LEY No 18.933 (2008): Tribunal Constitucional chileno, 20 de abril de 2010, Rol No 1273-08.

REQUERIMIENTO DE INAPLICABILIDAD POR INCONSTITUCIONALIDAD DE CATORCE COMPAÑIAS DE SEguRos GeNeRALES RESPECTO de LOS ARTículos $3^{\circ}$ Y $4^{\circ}$ DEL DECRETO LEY No 1.757, DE 1977 (2009): Tribunal Constitucional chileno, 6 de octubre de 2009, Rol No 1295-08.

REQUerimiento DE INAPLICABILIDAD POR INCONSTITUCIONALIDAD DEL JUEZ PRESIDENTE DEL JUZgado de Familia de Pudahuel, señor Carlo Marcelo Casaula Mezzano respecto del ARTÍCUlo 206 DEL CÓdigo CIVIL (2009): Tribunal Constitucional chileno, 29 de septiembre de 2009, Rol No 1340-09. 
REQUERIMIENTO DE INAPLICABILIDAD POR INCONSTITUCIONALIDAD DE LA CORTE DE APELACIONES DE TALCA, RESPECTO DEL ARTÍCULO 38 TER DE LA LEY No 18.933, EN ESPECIAL DE SU INCISO FINAL

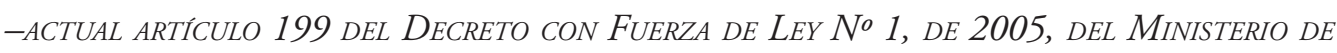
SALUD (2009): Tribunal Constitucional chileno, 27 de abril de 2010, Rol No 1348-09.

Sentencia recaída en el requerimiento de 10 Senadores de la República en contra de la constitucionalidad de determinados artículos del proyecto de ley que establece la Ley General de Educación (LEGE) (2009): Tribunal Constitucional chileno, 15 de mayo de 2009, Rol No 1361-09.

REQUERIMIENTO DE INAPLICABILIDAD POR INCONSTITUCIONALIDAD DE GUSTAVO IVAN QUILAQUEO Bustos RESPECTO DE LOS ARTÍCULOS 50, 60 $16,17,18$ Y $1^{\circ}$ TRANSITORIO, INCISO SEGUNDO, DE LA LEY No 19.970, QUE CREA EL SISTEMA NACIONAL DE REGISTROS DE ADN (2010): Tribunal Constitucional chileno, 8 de abril de 2010, Rol No 1365-09.

ACCIÓN DE INAPLICABILIDAD POR INCONSTITUCIONALIDAD DE INGENIERÍA Y CONSTRUCCIÓN PESADA Limitada (INCOPESA) RESPECTO DEL ARTÍCULO 43, $N^{\circ}$ 1, DE LA LEY $N^{\circ}$ 18.175, QUE MODIFICÓ Y FIJÓ EL NUEVO TEXTO DE LA LEY DE QUIEBRAS (2010): Tribunal Constitucional chileno, 14 de septiembre de 2010, Rol No 1414-09.

REQUERIMIENTO DE INAPLICABILIDAD POR INCONSTITUCIONALIDAD DE NELSON ARNALDO PINO SAN MARTIN RESPECTO DE LA ORACIÓN “CUANDO LO INTERPUSIERE EL MINISTERIO PÚBLICO”, CONTEnida en el inciso segundo del artículo 277 del Código Procesal Penal (2010): Tribunal Constitucional chileno, 9 de septiembre de 2010, Rol No 1502-09.

REQUERIMIENTO DE INAPLICABILIDAD POR INCONSTITUCIONALIDAD PRESENTADO POR EL JUEZ DE Familia de Pudahuel, Respecto de los artículos 206 del Código Civil y $5^{\circ}$ transitorio, INCISOS CUARTO Y FINAL, DE LA LEY No 19.585 (2011): Tribunal Constitucional chileno, 1 de septiembre de 2011, Rol No 1537-09.

REQUERIMIENTO DE INAPLICABILIDAD POR INCONSTITUCIONALIDAD PRESENTADO POR EL JUZGADO de Familia de VALdivia, Respecto del artículo 206 del Código CiVIL (2011): Tribunal Constitucional chileno, 30 de agosto de 2011, Rol No 1563-09.

REQUERIMIENTO DE INAPLICABILIDAD POR INCONSTITUCIONALIDAD PRESENTADO POR NEL GREEVEN Bobadilla, Juez de Familia de Pudahuel, Respecto del artículo 206 del Código CiVIL (2011): Tribunal Constitucional chileno, 1 de septiembre de 2011, Rol No 1656-10.

REQUERIMIENTO DE INAPLICABILIDAD POR INCONSTITUCIONALIDAD PRESENTADO POR JORGE WASHington Sepúlveda Álvarez respecto del artículo 365 del Código Penal, en la CaUsa (2011): Tribunal Constitucional chileno, 4 de enero de 2011, Rol No 1683-10.

PROCESO INICIADO DE OFICIO PARA DECIDIR SOBRE LA CONSTITUCIONALIDAD DEL ARTÍCULO 38 TER DE LA LEY DE ISAPRES Y CUYA SENTENCIA SE PUblicó EN EL Diario OfiCial EL 9 DE AGOSTO DE 2010 (2010): Tribunal Constitucional chileno, 6 de agosto de 2010, Rol No 1710-10.

REQUERIMIENTO DE INAPLICABILIDAD POR INCONSTITUCIONALIDAD PRESENTADO POR LA CORTE DE ApelaCiones de VALPARAISO RESPECTO DEL ARTÍCULO $4^{\circ}$ DE LA LEY No 19. 531, sustitUido POR EL ARTÍCULO $1^{\circ}$ DE LA LEY No 20.224 -QUE REAJUSTA E INCREMENTA LAS REMUNERACIONES Del Poder Judicial (2011): Tribunal Constitucional chileno, 24 de abril de 2011, Rol No 1801-10.

REQUERIMIENTO DE INCONSTITUCIONALIDAD PRESENTADO POR ISAPRE CRUZ BLANCA S.A. RESPECTO DEL ARTÍCULO $7^{\circ}$ DEL AUTO ACORDADO SOBRE TRAMITACIÓN Y FALLO DEL RECURSO DE PROTEC- 


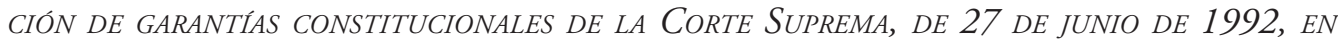
LOS AUTOS ROL No 3000-2010 SOBRE RECURSO DE PROTECCIÓN INTERPUESTO ANTE LA CORTE de Apelaciones de Santiago (SeCretaría CRIMINal) (2011): Tribunal Constitucional chileno, 18 de agosto de 2011, Rol No 1812-10.

REQUERIMIENTO DE INCONSTITUCIONALIDAD PRESENTADO POR ISAPRE CRUZ BLANCA S.A. RESPECTO DEL ART́́CULO $7^{\circ}$ DEL AUTO ACORDADO SOBRE TRAMITACIÓN Y FALLO DEL RECURSO DE PROTEC-

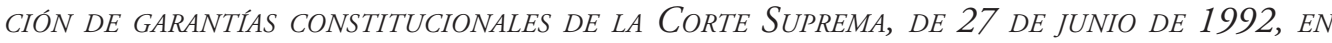
LOS AUTOS ROL No 2565-2010 SOBRE RECURSO DE PROTECCIÓN INTERPUESTO ANTE LA CORTE de Apelaciones de Santiago (Secretaría Criminal) (2011): Tribunal Constitucional chileno, 18 de agosto de 2011, Rol No 1816-10.

REQUERIMIENTO DE INCONSTITUCIONALIDAD PRESENTADO POR ISAPRE CRUZ BLANCA S.A. RESPECTO DEL ARTÍCULO $7^{\circ}$ DEL AUTO ACORDADO SOBRE TRAMITACIÓN Y FALLO DEL RECURSO DE PROTECCIÓN DE GARANTÍAS CONSTITUCIONALES DE LA CORTE SUPREMA, DE 27 DE JUNIO DE 1992, eN LOS AUTOS ROL No 2270-2010 SOBRE RECURSO DE PROTECCIÓN INTERPUESTO ANTE LA CORTE de Apelaciones de Santiago (Secretaría Criminal) (2011): Tribunal Constitucional chileno, 18 de agosto de 2011, Rol No 1817-10.

REQUERIMIENTO DE INAPLICABILIDAD POR INCONSTITUCIONALIDAD PRESENTADO POR ALFONSO ENRIque Paillaleve Quinan respecto del artículo 75, inciso primero, de la Ley No 18.695, Organica Constitucional de Municipalidades, en los aUtos Rol No 439-10-P, SOBRE SOLICITUD DE REMOCIÓN DE CARGO DE CONCEJAL POR INCOMPATIBILIDAD, SEGUIDOS ANTE EL TRIBUNAL REGIONAL ELECTORAL DE LA REGIÓN DE LOS LAGOS (2012): Tribunal Constitucional chileno, 31 de enero de 2012, Rol No 1941-11.

REQUERIMIENTO DE INAPLICABILIDAD POR INCONSTITUCIONALIDAD PRESENTADO POR ANGÉLICA DEL Carmen Ormazabal ARAVEna respecto del artículo 38, 38 ter de la LEY No 18.933, $2^{\circ}$ DE LA LEY No 20.015 y 199 DEL DFL. No1 DEL MINISTERIO DE SALUD, DE 2005, EN LOS aUtOS ROL No 1431-2011 SOBRE APELACIÓN DE PROTECCIÓN INTERPUESTO ANTE LA CORTE SUPREMA EN CONTRA DE LA SENTENCIA PRONUNCIADA POR LA CORTE DE APELACIONES DE SANTIAGO (SECRETARÍA CRIMINAL) QUE RECHAZÓ EL RECURSO DE PROTECCIÓN INTERPUESTO EN CONTRA DE ISAPRE VIDA TRES S.A EN CAUSA ROL No 8090-2010 (2012): Tribunal Constitucional chileno, 18 de agosto de 2011, Rol No 1958-11.

REQUERIMIENTO DE INCONSTITUCIONALIDAD PRESENTADO POR NEL GREEVEN BOBADILLA RESPECTO del artículo 206 del Código CIVIL (2013): Tribunal Constitucional chileno, $21 \mathrm{de}$ marzo de 2013, Rol No 2081-11.

REQUERIMIENTO DE INAPLICABILIDAD POR INCONSTITUCIONALIDAD PRESENTADO POR HERNÁN DEL TRÁnsito Orellana BaEZ (2012): Tribunal Constitucional chileno, 16 de octubre de 2012, Rol No 2110-11.

REQUERIMIENTO DE INAPLICABILIDAD POR INCONSTITUCIONALIDAD PRESENTADO POR EL BANCO DE ChILE RESPECTO DE LA ORACIÓN FINAL DEL ARTÍCULO 4으. INCISO PRIMERO, DE LA LEY 19.886 de Bases sobre Contratos Administrativos de Suministro y Prestación de Servicios (2013): Tribunal Constitucional chileno, 4 de julio de 2013, Rol No 2133-11.

CONTROL DE CONSTITUCIONALIDAD DEL PROYECTO DE LEY QUE ESTABLECE MEDIDAS CONTRA LA DISCRIMINACIÓN. (2012): Tribunal Constitucional chileno, 28 de junio de 2012, Rol No 2231-12. 
REQUERIMIENTO DE INAPLICABILIDAD POR INCONSTITUCIONALIDAD PRESENTADO POR CAROLINA Andrea Llanos Ojeda, Juez titular del Juzgado de Garantía de San Pedro de La Paz, y Luz Adriana Celedón Bulnes y Paola Andrea Rivas Mardones, Juezas titulares del CuARto JuzGado de Familia de SANTIAGO, RESPECTO DE LA PRIMERA PARTE DEL INCISO SEGUNDO DEL ARTÍCULO $6^{\circ}$ DE LA LEY $N^{\circ}$ 20.545, QUE MODIFICA LAS NORMAS SOBRE PROTECCIÓN A LA MATERNIDAD E INCORPORA EL PERMISO POSTNATAL PARENTAL (2013): Tribunal Constitucional chileno, 18 de junio de 2013, Rol No 2250-12.

Control de CONSTituCionalidad DEL PROYeCto DE LEY QUE ESTABLECE EL Sistema DE ELECciones Primarias para la nominación de candidatos a Presidente de la República, ParLAMENTARIOS Y ALCALDES (2012): Tribunal Constitucional chileno, 20 de noviembre de 2012, Rol No 2324-12.

REQUERIMIENTO DE INAPLICABILIDAD POR INCONSTITUCIONALIDAD PRESENTADO POR LEYLA ALEJANdra Chahín Valenzuela y otros Fiscales del Ministerio Público respecto del inciso SeGUNDO DEL ARTÍCULO 6 DE LA LEY N ${ }^{\circ}$ 20.545, QUE MODIFICÓ LAS NORMAS SOBRE PROTECCIÓN A LA MATERNIDAD E INCORPORÓ EL PERMISO POSTNATAL PARENTAL (2013): Tribunal Constitucional chileno, 4 de julio de 2013, Rol No 2357-12.

REQUERIMIENTO PRESENTADO POR UN GRUPO DE DIPUTADOS, QUE REPRESENTAN LA CUARTA PARTE DE LOS MIEMBROS EN EJERCICIO DE LA CAMARA DE DIPUTADOS, RESPECTO DE LA INCONSTITUCIONALIDAD DEL $N^{\circ} 9$ DEL ARTÍCULO ÚNICO DEL PROYECTO DE LEY QUE "PERMITE LA INTRODUCCIÓN DE LA TELEVISIÓN DIGITAL TERRESTRE" (2013): Tribunal Constitucional chileno, 9 de enero de 2013, Rol No 2358-12.

(ACUMULADA CON ROL No 2388-12) REQUERIMIENTO PRESENTADO POR UN GRUPO DE SENADORES, QUE REPRESENTAN MAS DE LA CUARTA PARTE DE LOS MIEMBROS EN EJERCICIO DEL SENADO, PARA QUE SE DECLARE LA INCONSTITUCIONALIDAD DEL ARTÍCULO $1^{\circ}$, NUMERALES 20, 3, LETRA C) Y 48 DEL PROYECTO DE LEY QUE MODIFICA, EN EL AMBITO DE LA SUSTENTABILIDAD DE RECURSOS HIDROBIOLÓGICOS, ACCESO A LA ACTIVIDAD PESQUERA INDUSTRIAL Y ARTESANAL Y REGULACIONES PARA LA INVESTIGACIÓN Y FISCALIZACIÓN, LA LEY GENERAL DE PESCA Y ACUICULTURA CONTENIDA EN LA LEY $N^{\circ} 18.892$ Y SUS MODIFICACIONES (2013): Tribunal Constitucional chileno, 23 de enero de 2013, Rol No 2387-12.

REQUERIMIENTO DE INAPLICABILIDAD POR INCONSTITUCIONALIDAD PRESENTADO POR LA I. MUNICipalidad de La Ligua Respecto del artículo 238 del Código de PRocedimiento CiVIL, EN RELACIÓN AL ARTÍCULO 32 DE LA LEY ORGÁNICA CONSTITUCIONAL DE MUNICIPALIDADES (2014): Tribunal Constitucional chileno, 24 de junio de 2014, Rol No 2432-13.

REQUERIMIENTO DE INAPLICABILIDAD POR INCONSTITUCIONALIDAD PRESENTADO POR LA I. MUNICI-

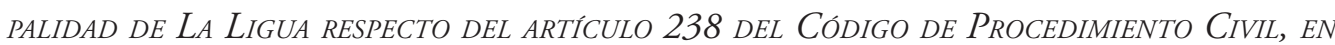

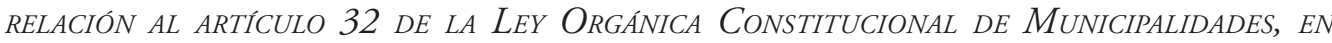
LOS AUTOS SOBRE COBRANZA LABORAL Y PREVISIONAL (2014): Tribunal Constitucional chileno, 1 de julio de 2014, Rol No 2433-13.

REQUERIMIENTO DE INAPLICABILIDAD POR INCONSTITUCIONALIDAD PRESENTADO POR INSICO S.A. RESPECTO DEL ARTÍCULO 32 DE LA LEY $N^{\circ}$ 18.695, MODIFICADO POR EL ARTÍCULO $1^{\circ}$ DE LA LEY $N^{\circ}$ 19.845 (2014): Tribunal Constitucional chileno, 10 de abril de 2014, Rol No 2438-13.

REQUERIMIENTO DE INAPLICABILIDAD POR INCONSTITUCIONALIDAD PRESENTADO POR LA CORTE SUPREMA RESPECTO DEL LITERAL C) DEL ARTÍCULO $3^{\circ}$ DE LA LEY $N^{\circ}$ 12.522, (2013): Tribunal Constitucional chileno, 24 de septiembre de 2013, Rol No 2440-13. 
REQUERIMIENTO DE INAPLICABILIDAD POR INCONSTITUCIONALIDAD PRESENTADO POR NORMA ISABEL TRONCOSO Donoso RespeCto de los artículos 197 bIS DEL Código deL TRABAJO, 7 Y 8 DEL DFL $N^{\circ}$ 44, del Ministerio de Trabajo y PReVisión Social, de 1978, 16 del DL 3.500 SOBRE NUEVO SISTEMA DE PENSIONES Y 6 DE LA LEY $N^{\circ}$ 20.545, RELATIVO AL POST NATAL PARENTAL DE FUNCIONARIAS PÚBLICAS (2014): Tribunal Constitucional chileno, 19 de junio de 2014, Rol No 2482-13.

REQUERIMIENTO DE INAPLICABILIDAD POR INCONSTITUCIONALIDAD PRESENTADO POR HIPERMERCADO ARAUCO LIMITADA Y OTROS, RESPECTO DEL INCISO TERCERO DEL ARTÍCULO 53 DEL CÓDIGO TRIBUTARIO (2014): Tribunal Constitucional chileno, 15 de abril de 2014, Rol No 2489-13.

REQUERIMIENTO DE INAPLICABILIDAD POR INCONSTITUCIONALIDAD PRESENTADO POR ALEJANDRA Anabalón Zunino, otras Fiscales del Ministerio Público y Asociación Nacional de Fiscales del Ministerio Público, respecto de la primera parte del inciso segundo deL ARTÍCULO 6 DE LA LEY N 20.545, QUE MODIFICÓ LAS NORMAS SOBRE PROTECCIÓN A LA MATERNIDAD E INCORPORÓ EL PERMISO POSTNATAL PARENTAL, EN LOS AUTOS SOBRE RECURSO DE PROTECCIÓN (2014): Tribunal Constitucional chileno, 13 de marzo de 2014, Rol No 2503-13.

REQUERIMIENTO DE INCONSTITUCIONALIDAD PRESENTADO POR UN GRUPO DE SEÑORES DIPUTADOS, QUE REPRESENTAN MÁS DE LA CUARTA PARTE DE LOS MIEMBROS EN EJERCICIO, RESPECTO DEL DE-

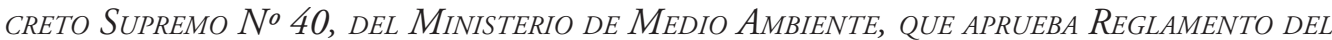
Sistema de EVALUaCión DE Impacto Ambiental, de 12 dE AGOSTO dE 2013 (2013): Tribunal Constitucional chileno, 30 de septiembre de 2013, Rol No 2523-13.

REQUERIMIENTO DE INCONSTITUCIONALIDAD PRESENTADO POR UN GRUPO DE DIPUTADOS, QUE REPRESENTAN LA CUARTA PARTE DE LOS MIEMBROS EN EJERCICIO DE LA CAMARA, RESPECTO DE LOS PRECEPTOS QUE INDICAN DEL PROYECTO DE LEY QUE PERMITE LA INTRODUCCIÓN DE LA TELEVISIÓN DIGITAL TERRESTRE (2013): Tribunal Constitucional chileno, 18 de noviembre de 2013, Rol No 2541-13.

\section{JURISPRUDENCIA CITADA DE OTROS TRIBUNALES NACIONALES}

Poblete con Servicio de Registro Civil e Identificación de Chile (2008): Corte de Apelaciones de Santiago, 11 de junio de 2008 (recurso de protección), Cita Online: CL/ JUR/2620/2008. Rol 2034-2008.

Municipalidad de Putre C. Comisión Regional del Medio Ambiente de Arica y Parinacota (2011): Corte de Apelaciones de Arica, 4 de marzo de 2011 (recurso de protección), Cita Online: CL/JUR/1783/2011. Rol 9-2011.

Margarita Ocares Castro con Universidad Central de Chile (2012): Primer Juzgado de Letras del Trabajo de Santiago, 5 de noviembre de 2012 (tutela laboral), Rol T-3672012, Cita Online: CL/JUR/3069/2012.

Corporación Metodista (1993): Corte Suprema, 25 de junio de 1993 (Recurso de implicabilidad), Rol 17.058 - 1993

\section{JURISPRUDENCIA EXTRANJERA CITADA}

Washington et al. V. GluCKSberg et al. Certiorari to the United States Court of Appeals for the ninth circuit. No. 96-110 (1997).

UNIVERSITY OF CALIFORNIA REGENTS V. BAKKE, 438 U.S. 265 (1978). 
